\title{
THE IMPLICATIONS OF STRUCTURAL ASYMMETRIES FOR MONETARY POLICY AND WELFARE IN A SMALL OPEN ECONOMY: A LINEAR QUADRATIC FRAMEWORK
}

\author{
Yuliya Rychalovska
}
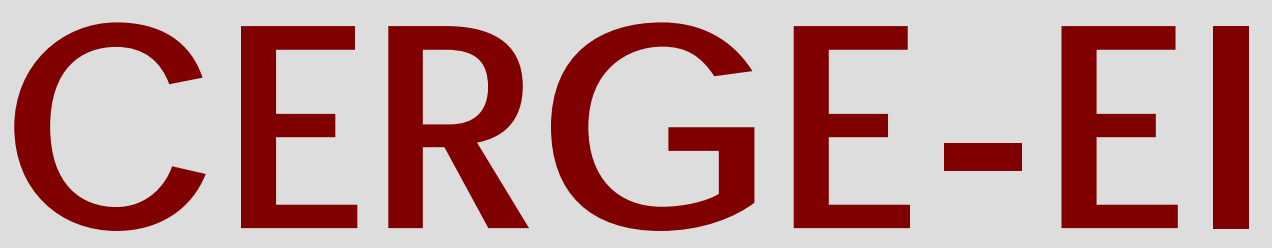

Charles University Centerfor Ec onomic Research and Graduate Education Academy of Sciences of the Czech Republic Ec onomic Institute 


\title{
Working Paper Series 380 (ISSN 1211-3298)
}

The Implications of Structural Asymmetries for Monetary Policy and Welfare in a Small Open Economy: A Linear Quadratic Framework

\author{
Yuliya Rychalovska
}

CERGE-EI

Prague, December 2008 
ISBN 978-80-7343-181-5 (Univerzita Karlova. Centrum pro ekonomický výzkum a doktorské studium)

ISBN 978-80-7344-170-8 (Národohospodářský ústav AV ČR, v.v.i.) 


\title{
The Implications of Structural Asymmetries for Monetary Policy and Welfare in a Small Open Economy: A Linear Quadratic Framework*
}

\author{
Yuliya Rychalovska ${ }^{\dagger}$ \\ CERGE-EI
}

December 2008

\begin{abstract}
The paper analyzes optimal monetary strategy and policy trade-offs in a DSGE model of an open economy with traded and non-traded sectors. We approximate the utility of the representative consumer to obtain a micro-founded quadratic loss function of the form extensively used for monetary policy assessment. The central bank's optimal strategy is computed and optimal and simple policy rules compared according to the derived welfare measure. The findings suggest that social welfare objectives display sector-specific features and prescribe the stabilisation of the appropriately weighted sectoral inflation rates and output gaps. A certain degree of the relative price management is also optimal. We analyze macroeconomic volatility and welfare losses under a number of simple policy rules and analyze their ability to replicate the optimal solution.

Tato práce analyzuje optimální měnovou strategii a měnově-politické konflikty v DSGE modelu otěvrené ekonomiky s obchodovatelným a neobchodovatelným sektorem. Aproximací užitku reprezentativního agenta je získána kvadratická ztrátová funkce ve formě, která je často používána pri hodnocení měnové politiky. Odvozená optimální strategie centrální banky je porovnávána s alternativními měnově-politickými pravidly pomocí odvozeného měřítka blahobytu. Výsledky naznačují, že společensky optimální měnová politika vykazuje sektorově specifické charakteristiky a vyžaduje stabilizaci př́slušně vážených měr inflace a mezer výstupu. Určitý stupeň relativního řízení cen je také optimální. Současně analyzujeme makroekonomickou volatilitu a ztráty společenského blahobytu spojené s několika rozličnými jednoduchými pravidly a posuzujeme jejich schopnost replikovat optimální řešení.
\end{abstract}

Keywords: DSGE models, non-traded goods, optimal monetary policy, welfare

JEL classification: E52, E58, E61, F41

\footnotetext{
*I would like to thank Gianluca Benigno, Jan Bruha, Sergey Slobodyan, and Henri Sneessens for useful comments and suggestions

$\dagger$ Email: yuliya.rychalovska@cerge-ei.cz

$\ddagger$ A joint workplace of the Center for Economic Research and Graduate Education, Charles Univer-
} 


\section{Introduction}

In the world of dynamic interactions between economies through international trade, should policymakers account for various country-specific features when implementing monetary strategy, or should they assume that welfare can be maximized under the uniform specification of the policy objectives? In other words, to what extent are the appropriate monetary policy targets endogenous to specific characteristics such as country size, degree of openness, asymmetric economic and trading structure, and the level of development across countries? This paper aims to contribute to the discussion of these crucial issues of monetary policy design and practical implementation.

The importance of taking a systematic approach to the conduct of monetary policy, featuring explicit formulation of policy objectives, has been rising in recent decades. Price stability has been recognized as the overriding policy goal by many monetary institutions worldwide. As a result, a new operational framework has been introduced by the most advanced central banks in order to match the officially stated goals of macroeconomic stabilization with their practical realization. Inflation targeting, which implies a quantitative specification of the desired level of inflation, has gained a reputation as being a strategy capable of generating stable and non-inflationary growth, thus strengthening the policy credibility and reputation of the monetary authority.

However, important features of modern economies, such as the social and economic consequences of unemployment, uncertainties of various types, asymmetric economic structure, and interrelations with the rest of the world, have brought about efforts to widen the range of policy objectives beyond inflation (price) stability alone. Therefore, over the past several years, the attention of leading economists has turned to the issue of formal characterization of the proper monetary policy objectives. These concerns have spurred a variety of research attempting to shed some light on the question of whether strict inflation targeting represents the optimal monetary policy from the welfare viewpoint. Addressing this topic is the most challenging when analyzing open economy models, where the formulation of policy targets appears to be more controversial compared to a closed economy setting.

The central issue in the literature on open economies is the assessment of the implications of openness for the formulation of a central bank's policy objectives and welfare analysis. In other words, the underlying questions are whether a central bank should also target open economy variables, i.e., the exchange rate, and how the targeting of domestic variables changes under the exposure of the economy to external

sity, Prague, and the Economics Institute of the Academy of Sciences of the Czech Republic. Address: CERGE-EI, P.O. Box 882, Politických vězňů 7, Prague 1, 111 21, Czech Republic 
factors. Answering these questions involves studying the conditions under which the open economy problem is not isomorphic to the closed economy model specification. Another topic which has attracted a great deal of attention from both researchers and practitioners is related to the determination of the appropriate inflation measure that has to be stabilized.

The problem of formal welfare analysis and the characterization of optimal monetary policy rules for different economic models have been addressed in a number of studies. It has been shown that welfare-maximizing monetary policy in a closed economy should aim to stabilize both CPI inflation and the output gap. Woodford (2003) derives the corresponding loss function from the utility of the representative household. In studies of open economies, the ranking of alternative monetary regimes and policy rules has been extensively performed on the basis of ad hoc objective functions or, alternatively, welfare representations derived for closed economy models.

A surprising conclusion drawn by several authors who have performed explicit welfare derivation for models of open economies is that exchange rate fluctuations have no direct impact on welfare. Specifically, Clarida, Gali, and Gertler (2001) find that under perfect exchange rate pass-through, the qualitative results for the closed economy carry over to the open economy. Gali and Monacelli (2005), who characterize the welfare of a small open economy for a special case of parameter values and under the balanced trade assumption, support the previous result and conclude that the small open economy problem is identical to that of a closed economy. The above results taken at face value imply optimality of complete exchange rate flexibility.

However, a number of recent studies have challenged this finding. Specifically, Corsetti and Pesenti (2005), Sutherland (2002), and Monacelli (2003) show that under incomplete pass-through, optimal policy is not purely inward looking. Benigno and Benigno (2006) analyze the gains from international monetary policy cooperation. They study the conditions under which individual countries have incentives to influence the terms of trade and thus to deviate from the socially optimal point. De Paoli (2006) finds that the simple violation of purchasing power parity (PPP), which arises from home bias in consumption, brings in a role for targeting the real exchange rate in a one-sector small open economy model. Liu and Pappa (2005) consider a two-sector, open economy model in a two-country framework. Their study provides interesting insights into the impact of an asymmetric structure between sectors on the gains from cooperation. Their results suggest that in an economy with multiple sectors, and thus multiple sources of nominal rigidities, optimal monetary policy cannot replicate a flexible price allocation creating the scope for coordination. The important limitation of their work for the analysis of optimal monetary policy is the assumption of unitary 
elasticity of substitution across goods and a logarithmic utility function. As a result, under this very special case, important welfare effects vanish and general conclusions concerning the optimal monetary policy cannot be derived.

The theoretical contributions discussed above mainly address the issue of the optimal monetary policy in stylized model frameworks that are derived from microfoundations, but, at the same time, they represent rather a simplified view of the real economy. Factors such as uncertainties, transmission mechanism lags, adjustment costs, and other country-specific characteristics are difficult to take into account in this class of models. Therefore, an alternative methodological approach, which allows the incorporation of more realistic features of real economies into the model, is now widely used in the literature and practice of central banks. This approach implies the derivation of the optimal policy rules on the basis of reduced-form model equations and an ad-hoc welfare function. Among the relevant contributions in the field is the paper by Hlédik (2003), who investigates the second-round effects of selected supply-side shocks and of shocks to the nominal exchange rate on wages and inflation. The author analyzes the optimal reaction of the central bank to these shocks and derives the optimal policy rules within the New-Keynesian framework. The reduced form approach employed in this paper allows us to incorporate a realistic (for the Czech economy) specification of wage contracts, to account for the delayed effects of monetary policy, and to include backward-looking components into the model. Consequently, the dynamics of the model are more realistic, which makes the results of such an analysis and the approach in general extremely useful for practical purposes.

Our work aims to analyze the stabilization objectives of optimal monetary policy and the trade-offs facing the central bank in a two-sector, small open economy model obtained as a limiting case of a two-country Dynamic Stochastic General Equilibrium framework. We assess the role of general preferences, structural asymmetries, and multiple relative prices for monetary policy design and welfare evaluation. Specifically, we aim to contribute to the normative analysis of open economies by introducing a more complicated economic structure, namely, multiple domestic sectors combined with a variety of sector-specific and foreign shocks. In addition, we consider a general specification of preferences. These features of the model differentiate our work from the previous studies, which derived their results for the special cases of unitary elasticity of substitution across goods or, alternatively, relied on the ad hoc objective functions and welfare representations obtained for closed economy models. By abstracting from those simplifying assumptions we are able to uncover additional welfare effects specific to the open multisectoral economy and make a methodological contribution by deriving the utility-based welfare measure and the optimal reaction function of the central 
bank under more generalized preferences. For this purpose we employ the linearquadratic solution methods discussed in Benigno and Benigno (2006) and Benigno and Woodford (2005), which involve computation of a second-order approximation of the model structural equations. This approach enables us to analyze the determinants of optimal monetary policy and rank alternative monetary policy regimes on the basis of a rigorous welfare measure derived from micro foundations and approximated by a tractable quadratic form.

The results of our study support the conclusion drawn by Benigno and Benigno (2006) and De Paoli (2006) that the optimal monetary policy for an open economy, in general, is not isomorphic to the one prescribed for the closed economy. Unlike the contributions mentioned above, our findings are determined by a multisectoral economic structure and, in particular, by the various sensitivities of the domestic sectors to exogenous shocks. We find that differentiating production between traded and nontraded goods in the open economy generates important implications for optimal policy and welfare. While in the closed economy setting the best strategy is determined purely by structural characteristics such as sector size or degree of nominal rigidities, the open economy formulation implies, in addition, openness to trade of one of the domestic segments. Such a qualitative difference between sectors determines their asymmetric response to exogenous shocks (even of identical magnitude) and brings sector-specific features into the formulation of stabilization objectives.

Moreover, our model representation provides important insights into the relevant policy trade-offs. In particular, we show that introducing the non-traded sector into the setup with general preferences allows the modeling of the endogenous conflict between the objectives of inflation and exchange rate stabilization in addition to the inflationoutput gap policy trade-off common in the literature. We would like to emphasize that under the special case of unitary elasticity of substitution and logarithmic utility, as in the two-sector model by Liu Pappa (2005), only the standard inflation-output gap trade-off can be generated. Thus, the crucial role of multiple relative prices in modeling another empirically appealing policy challenge disappears. Furthermore, we derive the optimal targeting rule, which determines the variables (targets) to which the central bank should respond in order to achieve efficient allocation of resources, as well as the magnitude of such a response. We show that the optimal targeting rule is represented by a complex expression that involves backward and forward-looking components. In general, the rule prescribes the response of the central bank to the appropriately specified measure of domestic inflation, sectoral output gaps, as well as to the relevant relative prices, i.e., the exchange rate and the relative price of non-traded goods. 
Finally, we experiment with alternative simple rules and analyze their ability to replicate the optimal solution. Such an exercise enables us to explicitly demonstrate and numerically evaluate policy trade-offs in terms of macroeconomic volatility. Our results suggest that targeting domestic inflation is not always the best approximation for the optimal policy, and social welfare can be improved by accounting for other policy objectives, namely, the output gap and the exchange rate. We present a ranking of alternative simple rules, which indicates the costs of implementing alternative monetary strategies and can provide useful information for managing the conflicting policy objectives. We show that the simple rules which incorporate a response to exchnage rate changes acheive better stabilization of sector-specific variables and thus improve welfare. Such a result is important because a strategy which differentiates the response between domestic sectors is difficult to design and implement in practice. Generally, the simple rules perform quite well in terms of macroeconomic stabilization (relative to the optimal rule) and can deliver reasonable welfare results.

The paper is organized as follows. Section 2 presents the model and section 3 describes the equilibrium dynamics. Section 4 analyzes the monetary policy problem and welfare. Section 5 describes the results of the numerical simulation. Section 6 illustrates the welfare implications of alternative simple rules. Finally, the results of the paper are summarized in section 7 .

\section{A Two-Sector, Small Open Economy Model}

The framework is represented by a two-country dynamic general equilibrium model where both sides, Home (the open economy $-H$ ) and Foreign (the rest of the world, the relatively closed economy $-F$ ), are explicitly modeled. The small open economy problem is derived as a limiting case of such a framework (as in De Paoli, 2006). Each country has two domestic sectors, which produce traded and non-traded goods; the share of non-traded goods may vary in the consumption basket of each country. A continuum of infinitively lived households consumes the final consumption good, which includes goods produced in both domestic sectors as well as imported goods. Households produce differentiated intermediate goods and receive disutility from production. We introduce monopolistic distortion and sticky prices in both sectors. These assumptions represent the standard way of introducing the role for monetary policy into such class of models. Households as consumers maximize their utility and solve the optimal price-setting problem as producers.

The model specification allows us to consider the closed economy, the open one- 
sector economy, and the economy with unitary elasticity of substitution as special cases of our more general analysis. We assume sector-specific productivity, fiscal, and markup shocks; the degree of nominal rigidities may also differ across sectors. Furthermore, we assume production subsidies in order to offset the monopolistic distortions in both sectors. The international and domestic asset markets are complete.

\subsection{Representative Households}

In our two-country framework a continuum of domestic households belong to the interval $[0, n)$, while foreign agents belong to the segment $(n, 1]$. The utility function of a representative consumer in country $H$ or $F$ is given by:

$$
U_{t}^{j}=E_{t}\left\{\sum_{s=t}^{\infty} \beta^{s-t}\left[U\left(C_{s}^{j}\right)-V\left(y_{s, T}(j), A_{s, T}^{i}\right)-V\left(y_{s, N}(j), A_{s, N}^{i}\right)\right]\right\},
$$

where $j$ is the index specific to the household, and $i$ is the country index; $E_{t}$ denotes the expectation operator conditional on the information set at time $t$, and $\beta$ is the intertemporal discount factor. $\mathrm{U}($.$) represents the flows of utility from consumption$ of a composite good and $V($.$) stands for the flows of disutility from production of$ differentiated goods. Each household produces two types of differentiated goods traded and non-traded. The home economy produces a continuum of differentiated traded goods indexed on the interval $[0, n]$, whereas the foreign economy's traded goods belong to the interval $(n, 1]$. In addition, a continuum of differentiated non-traded goods are indexed on the interval $[0, n]$ and $(n, 1]$ for the home and foreign country, respectively. $A$ denotes a productivity shock that can be country and sector specific. The subscript $T$ stands for the traded sector, whereas $N$ denotes the non-traded sector.

In our analysis we assume that preferences have isoelastic functional form:

$$
U\left(C_{s}^{j}\right)=\frac{\left(C_{s}^{j}\right)^{1-\rho}}{1-\rho}, \quad V\left(y_{s, L}(j), A_{s, L}^{i}\right)=\left(A_{s, L}^{i}\right)^{-\eta} \frac{\left(y_{s, L}(j)\right)^{1+\eta}}{1+\eta}
$$

where $L=H, N ; \rho>0$ is the inverse of the intertemporal elasticity of substitution in consumption, and $\eta \geq 0$ is equivalent to the inverse of the elasticity of goods production. The composite consumption good $C$ is a Dixit-Stiglitz aggregator of traded and nontraded goods defined as:

$$
C^{j}=\left[\gamma^{\frac{1}{\omega}}\left(C_{N}^{j}\right)^{\frac{\omega-1}{\omega}}+(1-\gamma)^{\frac{1}{\omega}}\left(C_{T}^{j}\right)^{\frac{\omega-1}{\omega}}\right]^{\frac{\omega}{\omega-1}}
$$

where $C_{N}$ and $C_{T}$ are the consumption sub-indexes that refer to the consumption of 
non-traded and traded goods, respectively, $\omega>0$ is the intratemporal elasticity of substitution, and $\gamma$ is a preference parameter that measures the relative weight that individuals put on non-traded goods.

Preferences for the rest of the world are specified in a similar fashion:

$$
C^{j *}=\left[\left(\gamma^{*}\right)^{\frac{1}{\omega}}\left(C_{N}^{* j}\right)^{\frac{\omega-1}{\omega}}+\left(1-\gamma^{*}\right)^{\frac{1}{\omega}}\left(C_{T}^{* j}\right)^{\frac{\omega-1}{\omega}}\right]^{\frac{\omega}{\omega-1}},
$$

where the asterisk denotes a foreign country variable.

Traded consumption goods are the aggregators of goods produced at home and abroad and defined as:

$$
\begin{aligned}
C_{T}^{j} & =\left[v^{\frac{1}{\theta}} C_{H}^{\frac{\theta-1}{\theta}}+(1-v)^{\frac{1}{\theta}} C_{F}^{\frac{\theta-1}{\theta}}\right]^{\frac{\theta}{\theta-1}} \\
C_{T}^{j *} & =\left[\left(v^{*}\right)^{\frac{1}{\theta}}\left(C_{H}^{*}\right)^{\frac{\theta-1}{\theta}}+\left(1-v^{*}\right)^{\frac{1}{\theta}}\left(C_{F}^{*}\right)^{\frac{\theta-1}{\theta}}\right]^{\frac{\theta}{\theta-1}},
\end{aligned}
$$

where $v$ and $v^{*}$ are the parameters that determine the preferences of agents in countries $H$ and $F$, respectively, for the consumption of goods produced at Home.

As in Sutherland (2002) and De Paoli (2006) we assume that $v^{*}$, the share of imported goods from country $H$ in the consumption basket of country $F$, increases proportionally to the relative size of the home economy $n$ and the degree of openness $\widetilde{v}^{*}$. Thus we assume that $v^{*}=n \cdot \widetilde{v}^{*}$. Similarly, $(1-v)=(1-n) \cdot \widetilde{v}^{*}$. Such a specification allows modeling of home bias in consumption as a consequence of different country size and degree of openness.

The consumption sub-indices of non-traded, home-produced, and foreign-produced differentiated goods are defined as follows:

$$
\begin{aligned}
C_{N}=\left[\left(\frac{1}{n}\right)^{\frac{1}{\sigma}} \int_{0}^{n} c_{N}(z)^{\frac{\sigma-1}{\sigma}} d z\right]^{\frac{\sigma}{\sigma-1}}, & C_{N}^{*}=\left[\left(\frac{1}{1-n}\right)^{\frac{1}{\sigma}} \int_{n}^{1} c_{N}^{*}(z)^{\frac{\sigma-1}{\sigma}} d z\right]^{\frac{\sigma}{\sigma-1}}, \\
C_{H}=\left[\left(\frac{1}{n}\right)^{\frac{1}{\sigma}} \int_{0}^{n} c_{h}(z)^{\frac{\sigma-1}{\sigma}} d z\right]^{\frac{\sigma}{\sigma-1}}, & C_{F}=\left[\left(\frac{1}{1-n}\right)^{\frac{1}{\sigma}} \int_{n}^{1} c_{f}(z)^{\frac{\sigma-1}{\sigma}} d z\right]^{\frac{\sigma}{\sigma-1}}, \\
C_{H^{*}}=\left[\left(\frac{1}{n}\right)^{\frac{1}{\sigma}} \int_{0}^{n} c_{h}^{*}(z)^{\frac{\sigma-1}{\sigma}} d z\right]^{\frac{\sigma}{\sigma-1}}, & C_{F}^{*}=\left[\left(\frac{1}{1-n}\right)^{\frac{1}{\sigma}} c_{n}^{1}(z)^{\frac{\sigma-1}{\sigma}} d z\right]^{\frac{\sigma}{\sigma-1}}
\end{aligned}
$$

where $\sigma>1$ is the elasticity of substitution across the differentiated goods.

The corresponding consumption-based price indexes for countries $H$ and $F$ take 
the form:

$$
\begin{aligned}
P & =\left[\gamma P_{N}^{1-\omega}+(1-\gamma) P_{T}^{1-\omega}\right]^{\frac{1}{1-\omega}} \\
P_{T} & =\left[v P_{H}^{1-\theta}+(1-v) P_{F}^{1-\theta}\right]^{\frac{1}{1-\theta}} \\
P^{*} & =\left[\left(\gamma^{*}\right)\left(P_{N}^{*}\right)^{1-\omega}+\left(1-\gamma^{*}\right)\left(P_{T}^{*}\right)^{1-\omega}\right]^{\frac{1}{1-\omega}} \\
P_{T}^{*} & =\left[\left(v^{*}\right)\left(P_{H}^{*}\right)^{1-\theta}+\left(1-v^{*}\right)\left(P_{F}^{*}\right)^{1-\theta}\right]^{\frac{1}{1-\theta}} .
\end{aligned}
$$

The price sub-indices for home, foreign, and non-traded goods in the two economies are:

$$
\begin{array}{ll}
P_{N}=\left[\left(\frac{1}{n}\right) \int_{0}^{n} p_{N}(z)^{1-\sigma} d(z)\right]^{\frac{1}{1-\sigma}} & P_{N}^{*}=\left[\left(\frac{1}{1-n}\right) \int_{n}^{1} p_{N}^{*}(z)^{1-\sigma} d(z)\right]^{\frac{1}{1-\sigma}}, \\
P_{H}=\left[\left(\frac{1}{n}\right) \int_{0}^{n} p_{h}(z)^{1-\sigma} d(z)\right]^{\frac{1}{1-\sigma}} & P_{F}=\left[\left(\frac{1}{1-n}\right) \int_{n}^{1} p_{f}(z)^{1-\sigma} d(z)\right]^{\frac{1}{1-\sigma}}, \\
P_{H}^{*}=\left[\left(\frac{1}{n}\right) \int_{0}^{n} p_{h}^{*}(z)^{1-\sigma} d(z)\right]^{\frac{1}{1-\sigma}} & P_{F}^{*}=\left[\left(\frac{1}{1-n}\right) \int_{n}^{1} p_{f}^{*}(z)^{1-\sigma} d(z)\right]^{\frac{1}{1-\sigma}},
\end{array}
$$

where $p_{N}(z), p_{H}(z)$, and $p_{F}(z)$ are prices in units of the domestic currency of the homeproduced non-traded and traded goods, and foreign-produced goods. The law of one price holds for differentiated goods, i.e., $p_{h}(z)=S \cdot p_{h}^{*}(z)$ and $p_{f}(z)=S \cdot p_{f}^{*}(z)$, where $S$ is the nominal exchange rate, defined as the price of the foreign currency in terms of the domestic currency. This in turn implies that $P_{H}=S \cdot P_{H}^{*}$ and $P_{F}=S \cdot P_{F}^{*}$. However, equations (1) and (2) demonstrate that the presence of non-traded goods and the home bias in consumption result in a violation of the Purchasing Power Parity (PPP), i.e., $P \neq S \cdot P^{*}$. Thus, the real exchange rate is not equal to one and is defined as $E R=\frac{S \cdot P^{*}}{P}$. The real exchange rate determinants will be more explicitly analyzed in subsection 2.5 .

\section{$2.2 \quad$ Aggregate Demand}

By solving the consumer's cost minimization problem, we derive the total demand for the differentiated goods produced in countries $H$ and $F$ as well as the demand for the non-traded goods in both countries. The resulting demand equations for country $\mathrm{H}$ 
take the following form:

$$
\begin{gathered}
\left.y_{h}^{d}(z)=\left(\frac{p_{h}(z)}{P_{H}}\right)^{-\sigma}\left[\begin{array}{c}
\left(\frac{P_{T}}{P}\right)^{-\omega}\left(\frac{P_{H}}{P_{T}}\right)^{-\theta} \times \\
\left\{\begin{array}{l}
v(1-\gamma) C+\left(\frac{1}{E R}\right)^{-\omega} \times \\
\left(\frac{v^{*}}{v+(1-v)\left(P_{F H}\right)^{1-\theta}}\right)+ \\
\left(\frac{1-v^{*}}{v\left(P_{F H}\right)^{\theta-1}+(1-v)}\right)
\end{array}\right]^{\frac{\theta-\omega}{1-\theta}}\left(1-\gamma^{*}\right) v^{*} C^{* \frac{1-n}{n}}
\end{array}\right\}+G_{H}\right] \\
y_{N}^{d}(z)=\left(\frac{p_{N}(z)}{P_{N}}\right)^{-\sigma}\left[\left(\frac{P_{N}}{P}\right)^{-\omega} \gamma C+G_{N}\right]
\end{gathered}
$$

and for goods produced in country F:

$$
\begin{gathered}
\left.y_{f}^{d}(z)=\left(\frac{p_{f}(z)}{P_{F}}\right)^{-\sigma}\left[\begin{array}{c}
\left(\frac{P_{T}}{P}\right)^{-\omega}\left(\frac{P_{F}}{P_{T}}\right)^{-\theta} \times \\
\left\{\begin{array}{c}
(1-v)(1-\gamma) C \frac{n}{1-n}+\left(\frac{1}{E R}\right)^{-\omega} \times \\
\left(\frac{v^{*}}{v+(1-v)\left(P_{F H}\right)^{1-\theta}}\right)+ \\
\left(\frac{1-v^{*}}{v\left(P_{F H}\right)^{\theta-1}+(1-v)}\right)
\end{array}\right]^{\frac{\theta-\omega}{1-\theta}}\left(1-\gamma^{*}\right)\left(1-v^{*}\right) C^{*}
\end{array}\right\}+G_{F}^{*}\right] \\
y_{N}^{d}(z)=\left(\frac{p_{N}^{*}(z)}{P_{N}^{*}}\right)^{-\sigma}\left[\left(\frac{P_{N}^{*}}{P^{*}}\right)^{-\omega} \gamma^{*} C^{*}+G_{N}^{*}\right]
\end{gathered}
$$

where $G$ and $G^{*}$ are country and sector-specific government purchase shocks, $P_{F H}=$ $\frac{P_{F}}{P_{H}}$ is the relative price of foreign to home-produced goods, i.e., the terms of trade, and $E R$ is the real exchange rate.

In order to obtain the small open economy version of our general two-country framework, we apply the assumptions $v^{*}=n \cdot \widetilde{v}^{*}$ and $(1-v)=(1-n) \cdot \widetilde{v}^{*}$ and take the limit $n \rightarrow 0$ similar to De Paoli (2006). As a result, the demand equations can be simplified to:

$$
\begin{gathered}
y_{h}^{d}(z)=\left(\frac{p_{h}(z)}{P_{H}}\right)^{-\sigma}\left[\begin{array}{l}
\left(\frac{P_{T}}{P}\right)^{-\omega}\left(\frac{P_{H}}{P_{T}}\right)^{-\theta} \times \\
\left\{v(1-\gamma) C+\left(\frac{1}{E R}\right)^{-\omega}\left[\left(\frac{1}{v\left(P_{F H}\right)^{\theta-1}+(1-v)}\right)\right]^{\frac{\theta-\omega}{1-\theta}}\left(1-\gamma^{*}\right) \widetilde{v}^{*} C^{*}\right\}+G_{H}
\end{array}\right] \\
y_{f}^{d}(z)=\left(\frac{p_{f}(z)}{P_{F}}\right)^{-\sigma}\left[\begin{array}{l}
\left(\frac{P_{T}}{P}\right)^{-\omega}\left(\frac{P_{F}}{P_{T}}\right)^{-\theta} \times \\
\left\{\left(\frac{1}{E R}\right)^{-\omega}\left[\left(\frac{1}{v\left(P_{F H}\right)^{\theta-1}+(1-v)}\right)\right]^{\frac{\theta-\omega}{1-\theta}}\left(1-\gamma^{*}\right) C^{*}\right\}+G_{F}^{*}
\end{array}\right] \cdot
\end{gathered}
$$

Therefore, the demand side for our two-sector, small open economy model is represented by equations (4), (6), (7), and (8). 
The demand equations illustrate the small open economy implications, the impact of the economic structure, and a more general specification of preferences. In particular, the demand for goods produced at Home depends on both domestic and foreign consumption, whereas the demand for foreign-produced goods is not affected by changes in Home consumption. Moreover, the two-sector model specification brings in the differentiated impact of the terms of trade and the real exchange rate on the total demand for tradable goods. This happens under the general assumption that $\theta \neq \omega$. The literature on open economies usually assumes that $\theta>\omega, \theta>1$, and $\omega$ is small. This implies that non-traded and traded goods are complements in the consumption basket. At the same time, home and foreign-produced goods are considered as substitutes.

\subsection{International Risk Sharing}

Foreign and domestic households have access to the international financial market, where state-contingent nominal bonds are traded. Households at home and abroad make their optimal consumption-saving decisions. They maximize their utility subject to the sequence of budget constraints for $t=0,1, \ldots$ :

$$
P_{t} C_{t}+E_{t} D_{t, t+1} B_{t+1} \leq B_{t}+\Pi_{t}+T_{t}
$$

where $B_{t+1}$ is the holding of a nominal state-contingent bond that pays one unit of home currency in period $t+1, D_{t, t+1}$ is the period $t$ price of the bond, $\Pi_{t}$ is the profit income from goods production, and $T_{t}$ is the transfer from the government. The complete-market assumption implies that the marginal rate of substitution between consumption in the two countries is equalized:

$$
\frac{U_{C}\left(C_{t+1}^{*}\right)}{U_{C}\left(C_{t}^{*}\right)} \frac{P_{t}^{*}}{P_{t+1}^{*}} \frac{S_{t}}{S_{t+1}}=\frac{U_{C}\left(C_{t+1}\right)}{U_{C}\left(C_{t}\right)} \frac{P_{t}}{P_{t+1}}
$$

The international risk-sharing equation presented above illustrates the equality of nominal wealth in both countries in all states and time periods. The violation of PPP implies that fluctuations in the real exchange rate may result in a divergence in consumption across countries even under optimal risk sharing.

Consumers' optimization problem implies the following Euler equation:

$$
U_{C}\left(C_{t}\right)=\beta\left[U_{C}\left(C_{t+1}\right) R_{t} \frac{P_{t}}{P_{t+1}}\right],
$$

where $R_{t}$ is the nominal interest rate. Log-linearization of this condition leads to the 
following expression:

$$
\widehat{r}_{t}=\rho\left(\widehat{C}_{t+1}-\widehat{C}_{t}\right)+E \pi_{t+1} .
$$

\subsection{Optimal Pricing Decisions}

Each household is a monopolistic producer of one differentiated traded and one nontraded good. The domestic household sets the price $p_{N}(z)$ and $p_{h}(z)$ and takes as given $P, P_{N}, P_{H}, P_{F}$, and $C$. The price-setting behavior is modeled according to Calvo (1983). In countries $H$ and $F$ in each time period a fraction $\alpha_{L} \in[0,1)$ of randomly picked producers in each sector $(L=N, H)$ are not allowed to change their prices. Thus the parameter $\alpha_{L}$ reflects the level of price stickiness. The remaining fraction $\left(1-\alpha_{L}\right)$ can choose the optimal sector-specific price by maximizing the expected discounted value of profits:

$$
E_{t} \sum_{S=t}^{\infty}\left(\alpha_{L} \beta\right)^{S-t}\left[\frac{U_{C}\left(C_{S}\right)}{P_{S}}\left(1-\tau_{S}\right) \widetilde{p}_{t, L}(z) \widetilde{y}_{t, S, L}(z)-V\left(\widetilde{y}_{t, S, L}(z), A_{S, L}\right)\right],
$$

where after-tax revenues in each sector are evaluated using the marginal utility of nominal income, $\frac{U_{C}\left(C_{S}\right)}{P_{S}}$, which is identical for all households in the country under the assumption of complete markets; $\tau_{S}$ is the tax rate; $\widetilde{p}_{t, L}(z)$ is the price of the differentiated good $z$, which is produced in sector $L$, chosen at time $t$, and $\widetilde{y}_{t, S, L}(z)$ is the total demand for good $z$, produced in sector $L$, at time $S$, conditional on the fact that the price $\widetilde{p}_{t, L}(z)$ has not been changed. All producers who belong to the fraction $\left(1-\alpha_{L}\right)$ choose the same price.

The optimal price $\widetilde{p}_{t, L}(z)$, which is derived from the first-order conditions, takes the following form:

$$
\widetilde{p}_{t, L}(z)=\frac{E_{t} \sum_{S=t}^{\infty}\left(\alpha_{L} \beta\right)^{S-t} V\left(\widetilde{y}_{t, S, L}(z), A_{S, L}\right) \widetilde{y}_{t, S, L}(z)}{E_{t} \sum_{S=t}^{\infty}\left(\alpha_{L} \beta\right)^{S-t} \frac{U_{C}\left(C_{S}\right)}{P_{S}} \frac{1}{\mu_{S}} \widetilde{y}_{t, S, L}(z)},
$$

where $\mu_{S, L}=\frac{\sigma}{\left(1-\tau_{S, L}\right)(\sigma-1)}$ represents the overall degree of monopolistic distortion and leads to an inefficient gap between the marginal utility of consumption and the marginal disutility of production. Benigno and Benigno (2006) and De Paoli (2006) refer to this gap as the mark-up shock. A Calvo-type setting implies the following law of motion for the sectoral price indices:

$$
P_{L, t}=\left[\alpha_{L}\left(P_{L, t-1}\right)^{1-\sigma}+\left(1-\alpha_{L}\right) \widetilde{p}_{t, L}(z)^{1-\sigma}\right]^{\frac{1}{1-\sigma}} .
$$


Similar conditions can be derived for the producers in country $F$.

\subsection{Real Exchange Rate Decomposition and PPP Violation}

In order to explore the structural economic factors that result in PPP violation, we consider the real exchange rate decomposition. The real exchange rate is defined as $E R=\frac{S \cdot P^{*}}{P}$. We use the price indexes (1), (1a), (2), and (2a) to express the real exchange rate as a function of relative prices and preference parameters. We also use the fact that the law of one price holds for tradable goods, i.e., $P_{H}=S \cdot P_{H}^{*}$ and $P_{F}=S \cdot P_{F}^{*}$. The real exchange rate can be presented as:

$$
E R=\left(\frac{v^{*}+\left(1-v^{*}\right)\left(P_{F H}\right)^{1-\theta}}{v+(1-v)\left(P_{F H}\right)^{1-\theta}}\right)^{\frac{1}{1-\theta}}\left(\frac{\gamma^{*}\left(P_{N T}^{*}\right)^{1-\omega}+\left(1-\gamma^{*}\right)}{\gamma\left(P_{N T}\right)^{1-\omega}+(1-\gamma)}\right)^{\frac{1}{1-\omega}},
$$

where $P_{F H}$ is the terms of trade defined in the previous sections, and $P_{N T}=\frac{P_{N}}{P_{T}}$ and $P_{N T}^{*}=\frac{P_{N}^{*}}{P_{T}^{*}}$ are the relative prices of non-traded goods in the two countries. Such a decomposition enables us to analyze the different channels of PPP violation. First of all, we note that under $v \neq v^{*}$, the $E R$ is affected by the terms of trade. For our small open economy model specification, given the assumptions on $v$ and $v^{*}$, the difference in country size necessarily results in different shares of consumption of home-produced goods in countries $\mathrm{H}$ and $\mathrm{F}$. This so-called home bias channel has also been analyzed by De Paoli (2006) and Sutherland (2002).

Another important component that explains the deviation of the $E R$ from PPP is determined by the multisectoral economic structure. Specifically, different preferences for consumption of non-traded goods across countries, i.e., $\gamma \neq \gamma^{*}$, as well as changes in the relative price of non-traded goods determine the fluctuation in the ER. The divergence in relative prices may occur as a result of country or sector-specific productivity shocks. Moreover, the law of one price holds for traded goods only. Nothing can ensure that the same equality will hold for the goods produced in the non-traded sector. Therefore, the exchange rate in our model is a composite term of two types of relative prices. As far as the policy issues are concerned, such a distinction implies a more difficult task of exchange rate management.

\section{Equilibrium Dynamics}

The equilibrium is described by the allocations of $C_{H, t}, C_{F, t}, C_{N, t}, B_{t+1}$ and $C_{H, t}^{*}, C_{F, t}^{*}$, $C_{N, t}^{*}, B_{t+1}^{*}$ for domestic and foreign households, respectively; the allocations of $y_{t, N}(z)$ 
and price $\widetilde{p}_{t, N}(z)$ for non-traded goods produced in country $\mathrm{H}$ and $y_{t, N}^{*}(z),{\widetilde{p^{*}}}_{t, N}(z)$ for the intermediate goods produced in country $\mathrm{F}$; the allocations $y_{t, H}^{d}(z)$ and price $\widetilde{p}_{t, H}(z)$ for traded goods produced in the domestic economy, and $y_{t, F}^{d}(z), \widetilde{p}_{t, N}(z)$ for traded goods produced abroad; and prices $D_{t, t+1}, S_{t}, E R_{t}, P_{t,} P_{N, t}, P_{T, t}, P_{H, t}, P_{t}^{*} P_{N, t}^{*}, P_{T, t}^{*}$, $P_{F, t}^{*}$ that satisfy the following equilibrium conditions:

1. taking prices as given, the household's allocation in each country solves the consumer's utility maximization problem;

2. taking aggregate prices as given, the demand allocations and the price of each non-traded differentiated good solve the producer's profit maximization problem;

3. taking aggregate prices as given, the demand allocations and the price of each traded differentiated good solve the producer's profit maximization problem;

4. the world bond market clears.

\subsection{Sticky Price Equilibrium}

The equilibrium dynamics under sticky prices are characterized by the optimality conditions derived in section 2. Here, we present a log-linearized version of the model. We define $\widehat{x_{t}} \equiv \ln \frac{x_{t}}{\bar{x}}$ as the $\log$ deviation of the equilibrium variable $x_{t}$ under sticky prices from its steady state value. $\widehat{x}_{t}^{\text {flex }} \equiv \ln \frac{x_{t}^{\text {flex }}}{\bar{x}}$ represents the $\log$ deviation of the equilibrium variable $x_{t}$ under flexible prices from its steady state value. Under the assumption of flexible prices, producers can re-optimize every period so that their pricing decisions are synchronized. As a result the price dispersion among the differentiated goods is zero. Therefore, the price index in each sector is equal to the price set by each producer in this sector, and the main source of domestic distortion is eliminated. We will refer to $\widehat{x}_{t}-\widehat{x}_{t}^{\text {flex }}$ as the deviation of the variable $\widehat{x}_{t}$ from its natural level, i.e., the gap. At the same time, Benigno and Woodford (2005) and De Paoli (2006) demonstrate that under certain conditions, the flexible price equilibrium does not represent the most efficient allocation of resources, and the desired levels of variables which the policymaker wishes to achieve in order to eliminate the loss may differ from the flexible price allocation. Specifically, in the presence of mark-up and fiscal shocks as well as the condition $\rho \theta \neq 1$, the flexible price allocation diverges from the desired targets. Therefore, in general, the optimal policy aims to stabilize of the variables relative to their target level. Thus, we define the welfare relevant gap as $\widehat{x}_{t}-\widehat{x}_{t}^{T}$, where $\widehat{x}_{t}^{T}$ is the target level of the variable $\widehat{x_{t}}$. Both the flexible price equilibrium and the target variables are functions of shocks that affect the economy. 
Moreover, we define the price change in the traded sector as $\Pi_{H}=\frac{P_{H, t}}{P_{H, t-1}}$ and that in the non-traded sector as $-\Pi_{N}=\frac{P_{N, t}}{P_{N, t-1}}$; consequently, the producer price inflation rates in the traded and non-traded sectors are $\pi_{H, t} \equiv \ln \left(\frac{P_{H, t}}{P_{H, t-1}}\right)$ and $\pi_{N, t} \equiv \ln \left(\frac{P_{N, t}}{P_{N, t-1}}\right)$, respectively. We approximate the model around the steady state, in which producer prices do not change, i.e., $\Pi_{H}=\frac{P_{H, t}}{P_{H, t-1}}=1$ and $\Pi_{N}=\frac{P_{N, t}}{P_{N, t-1}}=1$ at all times. A more detailed description of the steady state is presented in the Appendix.

\subsubsection{Log-Linearization of the Optimality Conditions}

We log-linearize the equilibrium conditions (4), (6)-(10), and (12) and obtain the following set of log-linear equations describing the dynamics of the multisectoral small open economy:

$$
\begin{aligned}
\pi_{H, t} & =k_{H}\left(\eta \widehat{Y}_{H, t}+\rho \widehat{C}_{t}+(1-v) \widehat{P}_{F H, t}+\gamma \widehat{P}_{N T, t}+\widehat{\mu}_{H, t}-\eta \widehat{A}_{H, t}\right)+\beta E_{t} \pi_{H, t+1}, \\
\pi_{N, t} & =k_{N}\left(\eta \widehat{Y}_{N, t}+\rho \widehat{C}_{t}-(1-\gamma) \widehat{P}_{N T, t}+\widehat{\mu}_{N, t}-\eta \widehat{A}_{N, t}\right)+\beta E_{t} \pi_{N, t+1}, \\
\widehat{Y}_{H, t} & =-[\theta+(\theta-\omega) v] \widehat{P}_{H T, t}+\omega \gamma \widehat{P}_{N T, t}+v \widehat{C}_{t}+w(1-v) \widehat{E R}_{t}+(1-v) \widehat{C}_{t}^{*}+\widehat{g}_{H, t}, \\
\widehat{Y}_{N, t} & =\widehat{C}_{t}-w(1-\gamma) \widehat{P}_{N T, t}+\widehat{g}_{N, t}, \\
\widehat{C}_{t} & =\frac{1}{\rho} \widehat{E R}_{t}+\widehat{C}_{t}^{*}, \\
\widehat{E R}_{t} & =v \widehat{P}_{F H, t}-\gamma \widehat{P}_{N T, t}+\gamma * \widehat{P}_{N T, t}^{*}, \\
\Delta \widehat{P}_{N T, t} & =\pi_{N, t}-\pi_{H, t}-(1-v) \Delta \widehat{P}_{F H, t} .
\end{aligned}
$$

Moreover, from the price index relation (1a) we note that:

$$
\widehat{P}_{H T, t}=-(1-v) \widehat{P}_{F H, t} .
$$

The Phillips curve relations in the two sectors are presented by equations (13) and (14), where $k_{L}=\frac{\left(1-\alpha_{L} \beta\right)\left(1-\alpha_{L}\right)}{\alpha_{L}(1+\sigma \eta)}$ is the constant that measures the response of the sectoral inflation rates to variations in real marginal costs. The characterization of real marginal costs in the open economy setting differs from that of the closed economy due to the gap between production and consumption as well as to the impact of relative prices, which reflect the distinction between domestic and consumer prices. An improvement in the terms of trade (a decrease in $\widehat{P}_{F H}$ ) or a positive productivity shock results in a fall in marginal costs in the traded sector. The marginal costs in the non-traded sector 
are independent of direct changes in the terms of trade. However, the sectoral marginal costs are linked through the relative prices of non-traded goods. This impact is opposite in sign and symmetric in magnitude. Producers' pricing decisions are forward-looking due to price stickiness. As a result, the Phillips curve takes the expectation-augmented form. Equations (15) and (16) describe the aggregate demand for domestic goods in

the two sectors. We consider $\widehat{C}_{t}^{*}$ as a term that cannot be affected by dynamics in the home country. This variable is exogenous from the small open economy perspective. Relation (17) is the log-linearized optimal risk-sharing condition. It describes variations in domestic consumption depending on fluctuations in the real exchange rate and consumption abroad. Equation (18), which is derived from (12), summarizes the determinants of the real exchange rate. Again, the relative price of non-traded goods in the foreign country is treated as exogenous. This equation illustrates the implication of the multisectoral economic structure. In particular, changes in the terms of trade do not necessarily imply a corresponding adjustment of the exchange rate, due to the impact of the relative prices of non-traded goods at home and abroad. Finally, expression (19), which is in fact an identity, is obtained from the definitions of non-traded and traded goods inflation and describes the evolution of the price indexes for both sectors. The equation that characterizes traded goods inflation is presented in the next sub-section.

\subsubsection{Domestic Inflation, CPI Inflation, and Some Aggregation Results}

In this sub-section, we present several useful definitions and identities, which will be used in the subsequent analysis. Log-linearization of price indexes (1) and (1a) yields :

$$
\begin{aligned}
\widehat{P}_{t} & =\gamma \widehat{P}_{N, t}+(1-\gamma) \widehat{P}_{T, t} \\
\widehat{P}_{T, t} & =v \widehat{P}_{H, t}+(1-v) \widehat{P}_{F, t} .
\end{aligned}
$$

Applying the definition of inflation $\pi_{t}=\ln \left(\frac{P_{t}}{P_{t-1}}\right)=\widehat{P}_{t}-\widehat{P}_{t-1}$, we obtain the expressions for CPI inflation and traded inflation:

$$
\begin{aligned}
\pi_{t} & =\gamma \pi_{N, t}+(1-\gamma) \pi_{T, t} \\
\pi_{T, t} & =v \pi_{H, t}+(1-v) \pi_{F, t} .
\end{aligned}
$$

Moreover, the definition of the terms of trade implies that $\pi_{F, t}=\Delta \widehat{P}_{F H, t}+\pi_{H, t}$. The combination of the equations presented above results in the following relationship between CPI and domestic inflation:

$$
\pi_{t}=\pi_{t}^{D}+(1-\gamma)(1-v) \Delta \widehat{P}_{F H, t},
$$


where domestic inflation equals:

$$
\pi_{t}^{D}=\gamma \pi_{N, t}+(1-\gamma) \pi_{H, t}
$$

Total output is given by:

$$
P_{t} Y_{t}=P_{N, t} Y_{N, t}+P_{H, t} Y_{H, t}
$$

Log-linearization of equation (26) yields:

$$
\widehat{Y}_{t}=\gamma \widehat{Y}_{N, t}+(1-\gamma) \widehat{Y}_{H, t}-(1-\gamma)(1-v) \widehat{P}_{F H, t}
$$

This relation implies that in an open multi-sectoral economy, aggregate output is not only the weighted average of the sectoral outputs, but also a function of relative prices.

Moreover, the evolution of the nominal exchange rate is derived from the definition of the real exchange rate and takes the form:

$$
\widehat{E R}_{t}-\widehat{E R}_{t-1}=\widehat{S}_{t}-\widehat{S}_{t-1}+\pi_{t}^{*}-\pi_{t}
$$

where $\widehat{S}_{t}$ is the nominal exchange rate, and $\pi_{t}^{*}$ is CPI inflation for the foreign country. We assume that the monetary authority abroad is implementing an inflation-targeting policy, and thus, $\pi_{t}^{*}=0$. Such an assumption is common in the small open economy literature (Gali and Monacelli, 2005).

\section{The Monetary Policy Problem and Welfare}

This section will present the formulation of the monetary policy strategy and an analysis of the competing objectives of the central bank. We will see that the model specification implies deviations of the optimal monetary policy from complete price stabilization. Specifically, we present a formal welfare analysis and derive the objective function of the central bank based on a second-order approximation of both the household's utility and the structural equilibrium conditions (13)-(19). Optimal monetary strategy involves the maximization of the quadratic social welfare function (a minimization of the loss function) subject to linear constraints. Monetary policy is able to achieve the best outcome from the welfare perspective by implementing the optimal plan. In this analysis, we focus on optimal targeting rules, which are strongly advocated by Svensson and Woodford. 


\subsection{The Objective Function of the Central Bank for an Open Economy with Multiple Domestic Sectors}

In order to obtain the analytical expression for welfare in a purely quadratic form, we apply the linear-quadratic solution methods described in Woodford (2003) and Benigno and Woodford (2005). This approach is based on the idea presented in Sutherland (2002) to explore the dynamic characteristics of the model and thus to account for the impact of the second moments of the variables on their levels. The derivation of the objective function of the central bank is presented in the Mathematical Appendix. We show that the utility function of the representative household can be approximated by the following expression:

$$
\begin{aligned}
W_{t o}= & U_{C} \bar{C} E_{t_{0}} \sum_{t=t_{0}}^{\infty} \beta^{t-t_{0}} \times \\
& {\left[\begin{array}{c}
\widehat{C}_{t}-\left(\bar{\mu}_{N}\right)^{-1} \gamma \widehat{Y}_{N, t}-\left(\bar{\mu}_{H}\right)^{-1}(1-\gamma) \widehat{Y}_{H, t}+\frac{1}{2}(1-\rho) \widehat{C}_{t}^{2} \\
-\frac{1}{2}\left(\bar{\mu}_{N}\right)^{-1} \gamma(1+\eta) \widehat{Y}_{N, t}^{2}-\frac{1}{2}\left(\bar{\mu}_{H}\right)^{-1}(1-\gamma)(1+\eta) \widehat{Y}_{H, t}^{2} \\
+\left(\bar{\mu}_{N}\right)^{-1} \gamma \eta \widehat{A}_{N, t} \widehat{Y}_{N, t}+\left(\bar{\mu}_{H}\right)^{-1}(1-\gamma) \eta \widehat{A}_{H, t} \widehat{Y}_{H, t} \\
-\frac{1}{2} \gamma \frac{\sigma}{\bar{\mu}_{N} k_{N}} \pi_{N, t}^{2}-\frac{1}{2}(1-\gamma)_{\frac{\sigma}{\bar{\mu}_{H} k_{H}}} \pi_{H, t}^{2}+t . i . p+\left(\left\|\xi^{3}\right\|\right)
\end{array}\right] . }
\end{aligned}
$$

We eliminate the linear terms in the objective function by using a second-order approximation of the equilibrium structural equations (13-19). As a result, we obtain an objective function that is purely quadratic. The expression takes the following form:

$$
\begin{aligned}
L_{t o}= & U_{C} \bar{C} E_{t o} \sum_{t=t_{0}}^{\infty} \beta^{t-t_{0}} \times \\
& {\left[\begin{array}{c}
\frac{1}{2} W_{Y_{N}}\left(\widehat{Y}_{N, t}-\widehat{Y}_{N, t}^{T}\right)^{2}+\frac{1}{2} W_{Y_{H}}\left(\widehat{Y}_{H, t}-\widehat{Y}_{H, t}^{T}\right)^{2}+\frac{1}{2} W_{E R}\left(\widehat{E R}_{t}-\widehat{E R}_{t}^{T}\right)^{2} \\
+\frac{1}{2} W_{P_{N T}}\left(\widehat{P}_{N T, t}-\left(\widehat{P}_{N T, t}^{T}\right)^{2}+W_{Y_{N} Y_{H}}\left(\widehat{Y}_{N, t}-\widehat{Y}_{N, t}^{T}\right)\left(\widehat{Y}_{H, t}-\widehat{Y}_{H, t}^{T}\right)\right. \\
+W_{E R, P_{N T}}\left(\widehat{E R}_{t}-\widehat{E R}_{t}^{T}\right)\left(\widehat{P}_{N T, t}-\widehat{P}_{N T, t}^{T}\right)+\frac{1}{2} W_{\pi_{N}}\left(\pi_{N, t}\right)^{2}+\frac{1}{2} W_{\pi_{H}}\left(\pi_{H, t}\right)^{2}
\end{array}\right]+t . i . p }
\end{aligned}
$$

where $\widehat{Y}_{N, t}^{T}, \widehat{Y}_{H, t}^{T}, \widehat{E R}_{t}^{T}$, and $\widehat{P}_{N T, t}^{T}$ are welfare-relevant target variables, which are functions of stochastic shocks and, in general, may not be identical to the flexible price allocations.

Equation (29) implies that the social welfare of the two-sector, small open economy is affected by deviations in the sectoral inflation rates, output gaps, and relative prices from their target values.

In fact, the objective function reflects the impact of various economic distortions on social welfare and illustrates their relative contributions to the loss. First of all, 
price rigidities and monopolistic distortions in both sectors, which may not be fully offset by production subsidies, result in economic inefficiencies and introduce a role for inflation and output gap stabilization. The cross-output variable $\left(\widehat{Y}_{N, t}-\widehat{Y}_{N, t}^{T}\right)\left(\widehat{Y}_{H, t}-\right.$ $\widehat{Y}_{H, t}^{T}$ ) describes the impact of co-movement in the sectoral output gaps on social welfare. When the weight in the objective function associated with the interaction term is positive, the sectoral asymmetries might be welfare improving. When this weight is negative, a co-movement of the sectoral outputs reduces welfare losses. In general, the weights next to each of the quadratic terms are represented by complicated functions of the structural parameters of the model (details are presented in the Appendix).

Furthermore, when price rigidities are present in both sectors and domestic shocks are imperfectly correlated, price changes are not synchronized following a shock. This results in inefficient output dispersion between sectors and introduces a role for relative prices into the monetary policy design problem. In this case, not only do the levels of inflation in both sectors matter for welfare, but so does the deviation of the relative price from its target level. The open economy formulation brings an additional, cross-country, dimension into the problem described above. Specifically, nominal rigidities may prevent prices in both countries from adjusting efficiently after exchange rate movements. In other words, the so-called relative price channel can fail to function accurately; this may result in welfare gains from exchange rate stabilization. On the other hand, in an open economy the policymaker can manipulate the terms of trade in order to increase expected consumption and decrease the expected disutility of production, i.e., to improve welfare. Those incentives are called the terms of trade externality and were analyzed by Benigno and Benigno (2006). Therefore, the weight next to the exchange rate term in the loss function balances the stability objective determined by the economic distortions (nominal rigidities) with the incentive of creating additional volatility in excess of the fundamental shocks. The cross factor $\left(\widehat{E R}_{t}-\widehat{E R}_{t}^{T}\right)\left(\widehat{P}_{N T, t}-\widehat{P}_{N T, t}^{T}\right)$ represents another "international dimension" term, which appears due to the fact that the relative price of non-traded to traded goods partially drives the evolution of the real exchange rate. This term, therefore, describes the additional welfare effects that originate from the correlation between the two relative prices.

Equation (29) indicates that the loss function derived for our model specification is not identical to the one of the closed economy or to the loss function obtained under the assumption $\rho=\theta=\omega=1$. The general welfare representation, however, embodies these two special cases, which coincide in terms of policy objectives and imply that $W_{Y_{N} Y_{H}}=0$ and $W_{E R}=W_{P_{N T}}=W_{E R, P_{N T}}=0$.

The presence of open economy terms is not the only implication of the exposure to external factors that can be observed in the objective function. The relative weights 
on the sectoral inflation rates and output gaps are not only affected by the structural asymmetries, like in the case of the closed economy, but also display the incentives that arise under openness to trade of one of the domestic sectors. Specifically, in an open economy, the weights in the objective function imply relatively higher stabilization of the non-traded sector compared to the traded sector variables. Figures 1 and 2 present the weights on inflation rates and output gaps as functions of the non-traded sector size derived for the closed and open economies, respectively. The weights are computed under the baseline parameterization.

Figure 1: Sector-Specific Weights for the Closed Economy Model
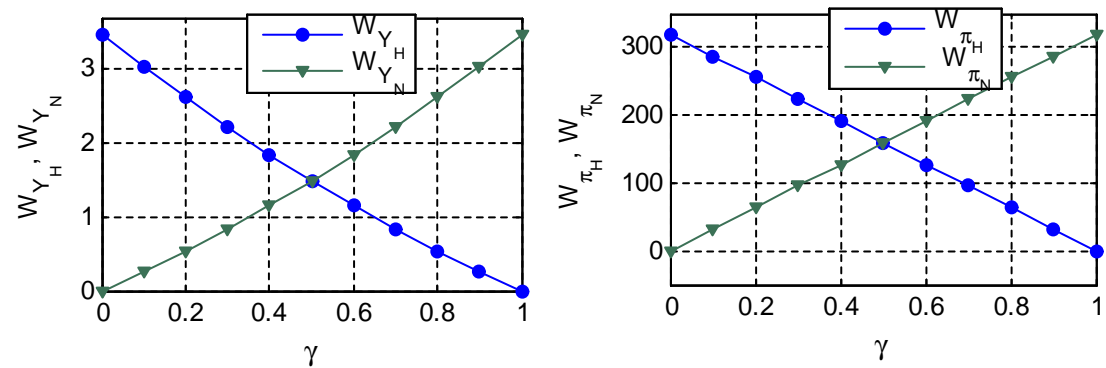

Figure 2: Sector-Specific Weights for the Open Economy Model
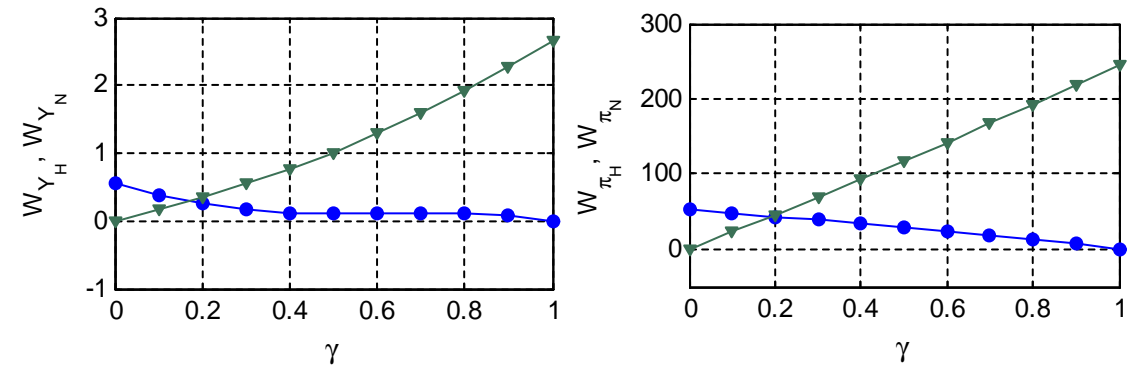

Two important results can be highlighted when analyzing Figures 1 and 2. First, these graphs indicate that both sectors are more volatile under the optimal policy when the economy is open (the weights are lower for all values of $\gamma$ ). Secondly, the decomposition of weights between sectors changes depending on whether the economy is subject to external factors. In particular, Figure 1 indicates that the weights derived for the closed economy model are symmetric and determined mainly by the parameter $\gamma$. The equal size of both sectors $(\gamma=0.5)$ implies their equal contribution to the loss function. In contrast, Figure 2 demonstrates that in the open economy, the stabilization "bias" is shifted toward the non-traded sector. In other words, the sector that is open to trade is allowed to adjust more at the optimum compared to the sector that 
produces goods only for internal consumption. Such a result is driven by incentives to explore the terms of trade externality in a welfare-improving manner combined with the monopolistic competition in the traded goods sector in countries $\mathrm{H}$ and $\mathrm{F}$ (measured by the parameter $\theta$ ). Specifically, domestic households can benefit from volatility in the traded sector by varying the consumption and output of home goods. The possibility to substitute for foreign goods in the consumption basket enables households to "divert" a part of production abroad and thus to lower the costs of the home-goods inflation and reduce the economic inefficiencies. Therefore, the terms of trade externality influences the weights of both the relative price terms and the domestic variables in the loss function. This effect is increasing in the elasticity of substitution between home and foreign traded goods $\theta$.

\subsection{The Optimal Monetary Policy Rules}

In order to obtain the optimal targeting policy rules, we minimize the objective function (29) subject to the set of constraints, which are given by:

$$
\begin{aligned}
& \pi_{H, t}=k_{H}\left[\eta\left(\widehat{Y}_{H, t}-\widehat{Y}_{H, t}^{T}\right)+\frac{1}{v}\left(\widehat{E R}_{t}-\widehat{E R}_{t}^{T}\right)+\frac{\gamma}{v}\left(\widehat{P}_{N T, t}-\widehat{P}_{N T, t}^{T}\right)+u_{t}^{H}\right]+\beta E_{t} \pi_{H, t+1}, \\
& \pi_{N, t}=k_{N}\left[\eta\left(\widehat{Y}_{N, t}-\widehat{Y}_{N, t}^{T}\right)+\left(\widehat{E R}_{t}-\widehat{E R}_{t}^{T}\right)-(1-\gamma)\left(\widehat{P}_{N T, t}-\widehat{P}_{N T, t}^{T}\right)+u_{t}^{N}\right]+\beta E_{t} \pi_{N, t+1}, \\
& \left(\widehat{Y}_{H, t}-\widehat{Y}_{H, t}^{T}\right)=\frac{l+1}{\rho v}\left(\widehat{E R}_{t}-\widehat{E R}_{t}^{T}\right)+\gamma\left[\frac{(l+1)+v^{2}(\rho \omega-1)}{\rho v}\right]\left(\widehat{P}_{N T, t}-\widehat{P}_{N T, t}^{T}\right)+\chi_{t}^{H} \\
& \left(\widehat{Y}_{N, t}-\widehat{Y}_{N, t}^{T}\right)=\frac{1}{\rho}\left(\widehat{E R}_{t}-\widehat{E R}_{t}^{T}\right)-\omega(1-\gamma)\left(\widehat{P}_{N T, t}-\widehat{P}_{N T, t}^{T}\right)+\chi_{t}^{N}, \\
& (1-v) \Delta\left(\widehat{E R}_{t}-\widehat{E R}_{t}^{T}\right)=v\left(\pi_{N, t}-\pi_{H, t}\right)-(v+\gamma(1-v)) \Delta\left(\widehat{P}_{N T, t}-\widehat{P}_{N T, t}^{T}\right)+\varepsilon_{t},
\end{aligned}
$$

where $l=(\rho \theta-1)(1-v)(1+v)$, and the terms $u_{t}^{H}, u_{t}^{N}, \chi_{t}^{H}, \chi_{t}^{N}, \varepsilon_{t}$ are functions of exogenous shocks and arise when the target levels of variables and flexible price allocations diverge. The conditions (30)-(34) are obtained by combining the log-linearized equilibrium conditions (13)-(19) and expressing the relations in terms of gap variables. We assume that the central bank can commit to the policy that maximizes welfare and consider the timeless perspective approach described in Woodford (2003). The timeless perspective optimal policy assigns the particular value to the commitment to expectations prior to period 0 . The constraints on the initial conditions result in the 
time-invariant first-order conditions and thus optimal policy. Therefore, the time inconsistency problem is eliminated. Following such a strategy, the policymaker chooses the path for endogenous variables $\pi_{H, t}, \pi_{N, t}, \widehat{Y}_{H, t}, \widehat{Y}_{N, t}, \widehat{E R}_{t}, \widehat{P}_{N T, t}$ subject to constraints (30)-(34) and given the initial conditions on $\pi_{H o}, \pi_{N o}, \widehat{Y}_{H o}, \widehat{Y}_{\text {No. }}$ The Lagrange multipliers associated with the set of constraints are $\lambda_{1, t}-\lambda_{5, t}$ respectively. In addition before the optimization, we divided equation (30) by $k_{H}$, equation (31) by $k_{N}$, and equation (34) by $v$. The first-order conditions to the problem are given by:

$$
\begin{aligned}
& W_{\pi_{H}} k_{H} \pi_{H, t}=\lambda_{1, t}-\lambda_{1, t-1}+\lambda_{5, t} k_{H}, \\
& W_{\pi_{N}} k_{N} \pi_{N, t}=\lambda_{2, t}-\lambda_{2, t-1}-\lambda_{5, t} k_{N} \text {, } \\
& W_{Y_{H}}\left(\widehat{Y}_{H, t}-\widehat{Y}_{H, t}^{T}\right)+W_{Y_{N} Y_{H}}\left(\widehat{Y}_{N, t}-\widehat{Y}_{N, t}^{T}\right)=\lambda_{3, t}-\eta \lambda_{1, t}, \\
& W_{Y_{N}}\left(\widehat{Y}_{N, t}-\widehat{Y}_{N, t}^{T}\right)+W_{Y_{N} Y_{H}}\left(\widehat{Y}_{H, t}-\widehat{Y}_{H, t}^{T}\right)=\lambda_{4, t}-\eta \lambda_{2, t}, \\
& W_{E R}\left(\widehat{E R}_{t}-\widehat{E R}_{t}^{T}\right)+W_{E R, P_{N T}}\left(\widehat{P}_{N T, t}-\widehat{P}_{N T, t}^{T}\right)= \\
& -\frac{1}{v} \lambda_{1, t}-\lambda_{2, t}-\frac{(l+1)}{\rho v} \lambda_{3, t}-\frac{1}{\rho} \lambda_{4, t}+\frac{1-v}{v}\left(\lambda_{5, t}-\beta \lambda_{5, t+1}\right) \\
& W_{P_{N T}}\left(\widehat{P}_{N T, t}-\widehat{P}_{N T, t}^{T}\right)+W_{E R, P_{N T}}\left(\widehat{E R}_{t}-\widehat{E R}_{t}^{T}\right)=-\frac{\gamma}{v} \lambda_{1, t}+(1-\gamma) \lambda_{2, t}- \\
& -\frac{\gamma\left(l+1+v^{2}(\rho \omega-1)\right)}{\rho v} \lambda_{3, t}+\omega(1-\gamma) \lambda_{4, t}+\left(1+\frac{(1-v) \gamma}{v}\right)\left(\lambda_{5, t}-\beta \lambda_{5, t+1}\right) .
\end{aligned}
$$

Combining equations (35)-(40), we can eliminate the Lagrange multipliers and express the optimal policy rule in the following general form:

$$
A^{0} \Delta \widetilde{X}_{t}+A^{1} \Delta \widetilde{X}_{t-1}+A^{2} \Delta \widetilde{X}_{t+1}=0
$$

where $A^{0}, A^{1}, A^{2}$ are the matrices of parameters, $\Delta \widetilde{X}_{t}=\widetilde{X}_{t}-\widetilde{X}_{t-1}$, and $\widetilde{X}_{t}=\widehat{X}_{t}-\widehat{X}_{t}^{T}$, i.e., $\widetilde{X}_{t}$ denotes the vector of the endogenous variables $\left(\pi_{H, t}, \pi_{N, t}, \widehat{Y}_{H, t}, \widehat{Y}_{N, t}, \widehat{E R}_{t}, \widehat{P}_{N T, t}\right)$ in deviations from their target values. Therefore, the optimal policy rule is represented by a fairly complicated expression that prescribes the response to deviations in the sectoral inflation rates and output gaps as well as to fluctuations in relative prices. The reaction function (41) includes both backward and forward-looking endogenous variables. The matrices of the parameters $A$, which describe the optimal magnitude of the response, depend on the optimal weights and the structural parameters of the model.

For comparison, the optimal policy rule derived with the use of the similar methodology for the one-sector, open economy model takes the general form: $A^{0} \Delta \widetilde{X}_{t}=0$. Therefore, the multi-sectoral model specification brings in more complex dynamics of 
variables under the optimal policy. Specifically, rule (41) is more persistent, i.e., it prescribes the response to the first and the second lag of the endogenous variables. Moreover, the rule contains forward-looking components since $A^{2} \neq 0$. The characteristics of the policy rule mentioned above are determined by the persistent structure of one of the model equations (34), which describes the evolution of the sector-specific inflation rates and the two types of relative prices.

\subsubsection{Policy Trade-Offs}

The welfare function (29) indicates that the monetary authority is confronted with several policy objectives. In particular, the central bank has to control the sector-specific inflation rates and output gaps, as well as relative prices. In order to study the optimal plan, it is important to investigate whether the policy goals can be simultaneously attained or the central bank has to decide how to balance them appropriately. Where the objectives do not conflict with each other, the central bank can achieve the first best allocation and completely eliminate the loss. In this section, we describe the policy trade-offs that arise in a generalized model of a two-sector, small open economy.

We analyze the combination of equations (18) and (19) expressed in terms of the welfare-relevant gap variables:

$$
(1-v) \Delta\left(\widehat{E R}_{t}-\widehat{E R}_{t}^{T}\right)=v\left(\pi_{N, t}-\pi_{H, t}\right)-(v+\gamma(1-v)) \Delta\left(\widehat{P}_{N T, t}-\widehat{P}_{N T, t}^{T}\right)+\varepsilon_{t}
$$

The gaps depend on the target levels of the variables, which in turn are functions of the shocks and parameters and vary over time. Equation (42) indicates that it is not possible to stabilize inflation rates in each sector and to eliminate the gaps between relative prices and their target values at the same time. In fact, relative prices act as endogenous shocks that do not allow the same policy to attain zero inflation in both sectors. For example, under a productivity shock in the non-traded goods sector (Figure 4), the optimal policy implies depreciation of the nominal exchange rate. Complete stability of non-traded inflation would require an even larger increase in the exchange rate. This, however, would result in a further worsening of the terms of trade and a greater rise in home-goods inflation. A similar trade-off exists under fiscal and mark-up shocks. Moreover, the impulse-responses indicate that the magnitude of the response differs across sector-specific variables. The different sensitivity of the domestic sectors to shocks is determined not only by structural asymmetries such as sector size, elasticity of substitution, and the level of nominal rigidities, but also by the openness to trade of one of the domestic sectors. Therefore, the optimal policy cannot comply with all the sector-specific stabilization objectives simultaneously. Woodford (2003) illustrates 
that a corresponding trade-off also exists in the closed economy model $(v=1)$ if the target rate of the relative price (the natural rate) is not constant.

Furthermore, we address the question of whether complete stability of the aggregate variables is attainable under the given economic structure. We present the Phillips curve relations in terms of gap variables and use the definition of domestic inflation. Moreover, in this analysis we assume for simplicity that the target variables and flexible price allocations coincide and the degree of nominal rigidities is equal across sectors. We combine the constraints (30)-(33) and apply the definition of domestic inflation (25). As a result, the following relationship arises:

$$
\pi_{t}^{D}=k\left[\begin{array}{c}
(\eta+\rho)\left(\gamma\left(\widehat{Y}_{N, t}-\widehat{Y}_{N, t}^{f l e x}\right)+(1-\gamma)\left(\widehat{Y}_{H, t}-\widehat{Y}_{H, t}^{f l e x}\right)\right)- \\
\frac{(1-\gamma)}{v} l\left(\widehat{E R}_{t}-\widehat{E R}_{t}^{f l e x}\right)-\frac{\gamma(1-\gamma)}{v} \widetilde{l}\left(\widehat{P}_{N T, t}-\widehat{P}_{N T, t}^{f l e x}\right)
\end{array}\right]+\beta E_{t} \pi_{t+1}^{D},
$$

where $l=(\rho \theta-1)(1-v)(1+v), \tilde{l}=l-(\rho \omega-1)(1-v) v$, and the flexible price allocations of the variables are functions of the exogenous shocks $\widehat{A}_{H, t}, \widehat{A}_{N, t}, \widehat{P}_{N T, t}^{*}, C_{t}^{*}$. Moreover, we make use of equation (26a) and provide the alternative domestic Phillips curve relation in order to analyze the impact of the aggregate output gap instead of the differentiation between the sectoral variables:

$$
\pi_{t}^{D}=k\left[\begin{array}{l}
(\eta+\rho)\left(\left(\widehat{Y}_{t}-\widehat{Y}_{t}^{\text {flex }}\right)+(1-\gamma)(1-v)\left(\widehat{P}_{F H, t}-\widehat{P}_{F H, t}^{f l e x}\right)\right)- \\
\frac{(1-\gamma)}{v} l\left(\widehat{E R}_{t}-\widehat{E R}_{t}^{f l e x}\right)-\frac{\gamma(1-\gamma)}{v} \widetilde{l}\left(\widehat{P}_{N T, t}-\widehat{P}_{N T, t}^{f l e x}\right)
\end{array}\right]+\beta E_{t} \pi_{t+1}^{D}
$$

We present two special cases of our more general analysis in order to describe the role of relative prices in generating the policy trade-offs. First, we consider a two-sector, closed-economy setting, i.e., $v=1, \gamma>0$. In such a situation $l=\widetilde{l}=0$. Equations (43) and (44) illustrate that the sectoral Phillips curves reduce to the classical aggregate relation, which, at the same time, describes the dynamics for the one-sector, closed economy. Therefore, there is no conflict between inflation and output gap stabilization, and optimal monetary policy is able to implement the first best, i.e., flexible price allocation. This result has been shown by Woodford (2003).

Secondly, we assume the special case of unitary elasticity of substitution and a unitary coefficient of relative risk aversion, i.e., the balanced trade model specification as in Liu and Pappa (2005). Again, we have $l=\widetilde{l}=0$. Thus, the exchange rate and relative prices vanish from the Phillips curve relations (43) and (44). Moreover, the assumption $\rho=\theta=\omega=1$ implies that the exchange rate does not characterize a welfare-relevant policy objective. In this situation, the terms of trade act as an endogenous "cost-push shock," which generates tension between domestic inflation and 
the output gap. In fact, such a trade-off can be generated in closed economy models in the presence of mark-up shocks or adjustment costs (Benigno and Woodford, 2005; Erceg and Levin, 2006).

Finally, we consider our two-sector model under general preferences. The Phillips curve (43) illustrates that the stabilization of domestic inflation and outputs in both sectors does not involve equivalent policies due to the presence of relative prices. Moreover, equation (44) indicates that there is tension between domestic inflation and exchange rate stability in addition to the trade-off between domestic inflation and the aggregate output gap variability. Therefore, unless preferences are specified in the general form, the conflict between managing domestic inflation and the real exchange rate ceases to exist.

The fairly complex economic structure and general model specification determine the non-trivial task facing policymakers, i.e., the search for the second-best optimal policy given that the flexible price efficient allocation of resources cannot be replicated. The optimal reaction function (41), in fact, represents such a second-best solution. A similar result is obtained in the one-sector, open-economy model analyzed by De Paoli (2006). In our case, however, the definition of the real exchange rate implies a distinction between the two types of relative prices and enables us to characterize the dynamics and impact of each variable separately. Moreover, the multiple sectors imply an additional policy challenge, i.e., the proper management of the "between-sector" terms.

\section{Impulse-Response Functions}

In this section we examine the impulse-responses of key macroeconomic variables to exogenous shocks. Specifically, we compare the numerical results under the optimal plan with the outcomes achieved under the basic simple rules common in the literature, such as domestic inflation targeting (DIT), consumer price index inflation targeting (CPIT), and an exchange rate peg (PEG). We consider four types of shocks, i.e., productivity, foreign, fiscal, and mark-up shocks. For the numerical exercise we assume the coefficient of relative risk aversion $\rho=3$ and the elasticity of substitution between differentiated goods $\sigma=10$ as in Benigno and Benigno (2006). Following Rotenberg and Woodford (1997) we set $\beta=0.99$ and $\eta=0.47$. The elasticity of substitution between traded home and foreign goods $\theta$ is assumed to be equal to 1.5 and the parameter that measures the substitution between non-traded and traded goods $\omega$ is set to 0.5 . The level of price rigidities $\alpha=0.66$, implying that the average length of price 
contracts is equal to 3 quarters. These assumptions are common in the open economy literature. In our benchmark specification we consider an equal level of price rigidities across sectors. Moreover, the share of non-traded goods in the consumption basket $\gamma$ is set to 0.5 . The corresponding parameter for the foreign country $\gamma^{*}=0.6$. The degree of openness $v=0.6$, implying a $40 \%$ import share. Finally, the steady state mark-up in the traded sector $\bar{\mu}_{H}$ is set to the value $1 / v$ as in Liu and Pappa (2005) and De Paoli (2006) in order to guarantee the optimal subsidy policy. In addition, the equal size of both domestic sectors implies that $\bar{\mu}_{H}=\bar{\mu}_{N}$. In this paper we assume that shocks are uncorrelated and have equal variance $\sigma^{2}=0.0001$. Shocks follow $\operatorname{AR}(1)$ process with autoregressive parameter equal to 0.7 .

Figure 3 represents the impulse-responses to a positive $1 \%$ productivity shock in the traded sector, $\widehat{A}_{H}$. All regimes (except PEG) imply a reaction of the monetary authority that induces a depreciation of the nominal exchange rate. Such dynamics, together with a fall in the price of home goods, worsen the terms of trade and thus result in a real depreciation. The increase in the exchange rate is the largest under DIT, because in this case the central bank stabilizes inflation more aggressively. In fact, higher home-goods inflation stability is traded for some additional exchange rate volatility. CPI inflation rises under DIT and the optimal plan. Here two effects are at work: the impact of the nominal exchange rate and the adjustment of the sectoral inflation rates after the productivity shock. Specifically, the increase in the exchange rate and prices in the non-traded sector dominate the fall in home-goods inflation, and the overall impact on CPI inflation is positive. Under PEG, the nominal exchange rate is stable and the effect of the productivity shock on CPI inflation is determined by the fall in inflation in the home-goods sector.

Domestic output increases due to the real exchange rate depreciation. Domestic goods become relatively cheaper than foreign goods. However, the increase in output is not large enough to boost production above its target level and the total impact on the output gap is negative. The expenditure switching effect is the most pronounced under the DIT regime, which implies no control over the exchange rate and thus allows for greater real depreciation. As a result, the output response is the largest. On the contrary, under PEG and CPIT the expenditure switching effect is minimized and the output gap falls by more compared to the other regimes.

The negative response of home-goods inflation under all the regimes is determined by the direct impact of the productivity shock, which lowers the marginal costs in this sector. However, the marginal costs in the non-tradable sector increase. Nontraded output increases and the relative price of non-traded to traded goods $\widehat{P}_{N T}$ falls under DIT and the optimal plan, due to nominal depreciation. As a result, non-traded 
inflation rises.

Figure 4 presents the impulse-response to a productivity shock in the non-traded sector, $\widehat{A}_{N}$. The dynamics of the variables can be described in a similar fashion. The shock lowers the marginal costs in the non-traded sector and inflation in this sector falls. As in the previous case, the reaction of the monetary authority causes depreciation of the nominal exchange rate. Both the fall in the price of non-traded goods and the nominal depreciation, which worsens the terms of trade, result in real depreciation. Inflation in the home-goods sector rises due to the increase in the terms of trade. It is important to note that non-traded inflation is stabilized to a greater extent under the optimal plan compared to the alternative simple rules. The reason for such a policy reaction is that the optimal welfare function assigns the greatest weight to stabilization of non-traded inflation. At the same time, the productivity shock $\widehat{A}_{N}$ directly affects the price change in this sector and, hence, induces greater dynamics of this variable. In order to prevent large swings in non-traded inflation, the central bank allows greater adjustments in relative prices and output. In addition, the response of relative prices $\left(\widehat{P}_{N T}\right.$ and $\left.\widehat{E R}\right)$ is almost two times stronger than the responses of these variables following the productivity shock $\widehat{A}_{H}$. Again, the reason is that instability of non-traded inflation has larger negative welfare consequences than changes in home-goods inflation.

The output reaction is positive in both sectors due to the large expenditure switching effect under DIT and the optimal plan. Unlike the negative response of the output gap following the productivity shock in the home-goods sector, the $\widehat{A}_{N}$ shock results in an increase of output above its target level due to the more expansionary policy.

Figure 5 presents the responses of domestic variables to the innovation in foreign consumption, $\widehat{C}^{*}$. We can observe that the DIT regime is very similar to the optimal plan in terms of the direction and magnitude of the response. The foreign consumption shock raises domestic consumption through the risk-sharing condition. This, in turn, may induce an increase in domestic output. At the same time, the nominal and real exchange rates appreciate and the terms of trade fall. Domestic goods become relatively less competitive and demand shifts to foreign goods. The net effect on home output is negative under DIT and the optimal plan. CPI inflation falls due to the exchange rate appreciation. At the same time the sectoral inflation rates show just a slight response to the shock. The impact of the shock on the macro-variables is qualitatively different under the CPIT and PEG regimes. Specifically, the monetary authority stabilizes relative prices and the real appreciation is small. The expenditure switching effect is dominated by the positive impact of the shock on domestic consumption and demand. As a result, the outputs in both sectors as well as the output gap show a significant 
increase. Such a boost in production increases marginal costs, and inflation in both sectors rises.

Figure 6 presents the impulse-responses to a shock to foreign relative prices, $\widehat{P}_{N T}^{*}$. An increase in the relative price of non-traded to traded goods abroad could be caused by a decrease in the price of foreign goods $P_{T}^{*}$ following the productivity shock in sector $F^{*}$. Again, the DIT regime almost perfectly replicates the optimal response. The reaction of the central bank results in a small nominal depreciation. The change in relative prices, however, is significant. The terms of trade fall sharply due to a decrease in the domestic currency price of foreign goods. The relative price of nontraded to traded goods increases. Domestic households substitute for cheaper goods in the consumption basket and demand in the home-goods production sector falls. Non-traded output remains almost unaffected due to the low elasticity of substitution between goods $N$ and $H$. CPI inflation falls following the decrease of the terms of trade, whereas the responses of the sectoral inflation rates are quantitatively small.

The policy reaction following the $\widehat{P}_{N T}^{*}$ shock displays a sharp contrast between the responses under the CPIT and PEG regimes, whereas under the other types of shocks these two regimes induce very similar changes in economic activity. Specifically, under the CPIT regime the central bank prevents large movements in the terms of trade at the expense of additional domestic inflation volatility. The policy implies a large nominal depreciation so as to mitigate the negative impact of foreign prices on the terms of trade. The nominal depreciation under the stabilized CPI inflation results in real depreciation. This, in turn, increases domestic production and inflation in both sectors. On the contrary, the PEG regime induces a policy that is closer to the optimal plan and DIT. Where foreign and home goods are substitutes, the optimal response implies a greater nominal exchange rate stabilization in order to improve the terms of trade and divert production abroad by switching to consumption of foreign goods. Such a policy is welfare improving because it enables one to take advantage of the foreign productivity shock by reducing domestic marginal costs and the inefficient output dispersion associated with price rigidities.

Figure 7 shows the impulse responses to a mark-up shock in the home-goods sector, $\widehat{\mu}_{H}$. The optimal policy diverges from complete domestic inflation stabilization and the other alternative simple rules. The positive shock leads to a rise in home-goods inflation, which returns to its initial level after several periods of deflation, and a temporary fall in the output gap. The extent to which the shock affects output versus inflation depends on the weight that the central bank places on output gap variability. Specifically, the optimal policy, unlike the alternative simple rules, implies a certain degree of output gap stability. Therefore, inflation is allowed to increase more and 
the output gap to fall less under the optimal plan. The response of the monetary authority to a mark-up shock implies fall in the nominal interest rate, depreciation of the exchange rate, an increase in the terms of trade, and a fall in the relative price of non-traded to traded goods. Outputs in both domestic sectors and consumption rise in response to a shock. The output gap, however, falls due to the fall in home-goods output below its target value.

The responses to a mark-up shock in the non-traded sector, $\widehat{\mu}_{N}$, are presented in figure 8. Again, the central bank has to balance conflicting policy objectives - to absorb the upward pressure on inflation in the non-traded sector by a fall in the output gap. The exchange rate appreciates and consumption and output decrease under the optimal plan. The DIT regime implies a greater economic contraction and thus the largest fall in output and consumption. CPIT and PEG represent strongly suboptimal regimes because they induce excessive stabilization of relative prices and a higher response of non-traded inflation.

The comparative analysis of impulse-responses under the $\widehat{\mu}_{H}$ and $\widehat{\mu}_{N}$ shocks suggests that the optimal policy reacts more aggressively under the disturbance to a non-traded mark-up. Such a response reflects the decomposition of weights in the welfare objective function, which assigns higher weights to the non-traded sector variables. The optimal policy implies more persistent economic contraction under the $\widehat{\mu}_{N}$ shock. The output gaps in both sectors and consumption fall and moderate the upward pressure on nontraded inflation, the variable which induces the largest welfare losses. As a result, the allowed non-traded inflation volatility following the $\widehat{\mu}_{N}$ shock is more than two times smaller than the response of home-goods inflation after the $\widehat{\mu}_{H}$ shock. In addition, the decrease in the output gap in the home-goods sector absorbs the major part of the positive upward pressure on inflation. In other words, the aggregate output gap changes to a greater extent due to the adjustment of the traded sector output gap, which is allowed to be more volatile under the optimal plan.

Figures 9 and 10 illustrate the responses to fiscal shocks in the traded and nontraded sectors, respectively. Again, the optimal policy differs significantly from the simple policy rules. The rise in government spending $\widehat{g}_{H}$ increases home-goods output. The central bank, which aims at domestic inflation stabilization, offsets the upward pressure on home-goods inflation by a corresponding decrease in non-traded inflation. The response induces an initial appreciation of the exchange rate, a fall in the terms of trade, and a rise in the relative price of non-traded to traded goods. As a result, consumption and non-traded output decrease. The optimal plan, on the contrary, implies an expansionary policy. The exchange rate depreciates, implying an additional stimulus to output in both domestic sectors. Such a policy prevents the initial drop in 
consumption. The CPI and PEG regimes imply greater stability of relative prices. A slight fall in the terms of trade turns out to be sufficient for consumer price stabilization.

The government spending shock $\widehat{g}_{N}$ increases non-traded output and creates upward pressure on non-traded inflation. Therefore, unlike in the previous case, the optimal policy implies the economic contraction. The response of the central bank is the most aggressive compared to the alternative policy rules. The nominal exchange rate sharply appreciates and output in the traded sector and consumption decrease. The relative price of non-traded to traded goods increases because non-traded goods become relatively scarce and import prices fall. As a result, greater non-traded inflation stability is achieved at the expense of additional volatility of inflation and output in the traded sector, as well as a larger adjustment of relative prices.

The analysis of the numerical results suggests that the type of shock and the economic structure are important determinants of the comparative performance of optimal versus simple policy rules. Specifically, the responses under the optimal policy differ the most from the simple rules under fiscal and mark-up shocks. On the contrary, the DIT regime better approximates the optimal plan under foreign and productivity shocks. In addition, the optimal and PEG regimes come closer under a foreign relative price shock. Shocks of the same type but affecting different domestic sectors may induce qualitatively distinct economic responses. This happens due to the different sensitivity of welfare-relevant economic variables to sector-specific shocks and greater stabilization of the non-traded sector under the optimal policy. In particular, the optimal policy is expansionary with respect to fiscal and mark-up shocks in the traded sector, whereas identical shocks in the non-traded sector call for an economic contraction.

The DIT regime induces a more expansionary policy under a traded-sector productivity shock, whereas the policy is less active following foreign shocks. Fiscal and mark-up disturbances result in an economic contraction under DIT. Under the CPI and PEG regimes, the policy is less aggressive in response to domestic productivity shocks and it becomes more expansionary under foreign shocks.

\section{Welfare Implications of the Alternative Simple Rules}

The study of the optimal policy problem presented in the previous sections provides a useful theoretical foundation for the design of monetary strategy and offers a rigorous benchmark for comparing the performance of alternative monetary regimes. At the 
same time, the prescriptions of the optimal policy given by expression (41) might be too difficult for the general public to interpret and too difficult to put into practice. Therefore, the analysis of the alternative policy rules, which deliver reasonable welfare results and at the same time are simple and transparent, and the optimal rule, which has normative implications, should interact in a complementary way in order to provide beneficial economic conclusions. In this section we enhance the analysis of the optimal policy with a discussion of the alternative simple rules and present their comparative performance. Specifically, we use Dynare software in order to compute optimal simple rules (OSRs) of the form: $r_{t}=r_{t-1}+k X+\epsilon_{t}$, where $X$ is a vector of endogenous variables, $k$ is a vector of optimized parameters, and $\epsilon_{t}$ is a policy shock with standard deviation set to 0.003.In fact, we compute the parameters of a policy rule which maximize a linear-quadratic loss function (29) subject to constraints (30-34). As a result, we are able to analyze the performance of rules with a simple structure but with optimal coefficients.

We address two important issues. First, we consider several types of alternative simple rules classified depending on the variables entering the rules and investigate the extent to which alternative monetary regimes are able to replicate the optimal solution. Secondly, we explore the implications of the alternative simple rules for macroeconomic volatility.

The welfare ranking is performed on the basis of the value of the loss, which is computed by taking the unconditional expectations of expression (29), i.e., the second-order approximation to the utility of the representative consumer, expressed as a fraction of the steady state consumption. As a result, we present the value of the loss in terms of the variances/covariances of the sector-specific inflation rates, output gaps, and relative prices:

$V \equiv \frac{1}{2} \frac{\beta}{1-\beta} \times\left[\begin{array}{c}W_{Y_{N}} \operatorname{var}\left(\widetilde{Y}_{N, t}\right)+W_{Y_{H}} \operatorname{var}\left(\widetilde{Y}_{H, t}\right)+2 W_{Y_{N} Y_{H}} \operatorname{covar}\left(\widetilde{Y}_{N, t} \widetilde{Y}_{H, t}\right)+ \\ +W_{E R} \operatorname{var}\left(\widetilde{E R}_{t}\right)+W_{P_{N T}} \operatorname{var}\left(\widetilde{P}_{N T, t}\right)+2 W_{E R, P_{N T}} \operatorname{covar}\left(\widetilde{E R}_{t} \widetilde{P}_{N T, t}\right)+ \\ +W_{\pi_{N}} \operatorname{var}\left(\pi_{N, t}\right)+W_{\pi_{H}} \operatorname{var}\left(\pi_{H, t}\right)\end{array}\right]$.

Table 1 reports the welfare losses associated with various types of OSRs. Specifically, we consider simple rules which include domestic variables and rules that prescribe the response to both closed and opened economy terms. In addition, we would like to evaluate the benefits of targeting sector-specific inflation rates and outputs versus aggregate variables. This issue is practically important since central banks do not usually differentiate their policy response depending on the economic sector and consider aggregate variables, due to the problem of policy implementation and a lack of information. 
Table 1 indicates that the welfare losses under the OSRs that target domestic inflation are on average 10-20\% larger compared to the optimal rule. The losses associated with CPI inflation targeting are significantly larger. The DIT regime performs worse compared to the results obtained in the previous literature. In particular, in the special case of the open economy model presented in Gali and Monacelli (2005) and the framework with ad-hoc welfare objectives as in Soto (2004), the DIT regime represents or nearly replicates the first-best. In our case, however, the ranking of alternative regimes suggests that strict inflation targeting is suboptimal compared to policies that account for other policy objectives. Specifically, the DIT strategy is dominated by the rules that prescribe the response to past interest rate and deviations in the output gap. Moreover, the rules that account for sector-specific variations in outputs perform better compared to the case of targeting the aggregate variable. At the same time, augmenting the rule that responds to domestic inflation and total output with the exchange rate term allows one to achieve a welfare result that is close to the case of targeting the traded and non-traded output gaps separately. Stabilization of the appropriately weighted average of the sectoral inflation rates (rule 10) produces better results than DIT. The welfare improvement constitutes around $10 \%$. Rule 11 indicates that even better result (in terms of welfare) can be achieved by targeting a combination of non-tradable inflation rate and the exchange rate changes. Furthermore, sector-specific inflation targeting is dominated by the strategies that incorporate the output and exchange rate policy objectives. The CPI and PEG regimes represent the least attractive alternatives to the optimal rule from the welfare viewpoint. The poor performance of strict CPI targeting can be explained by the excess smoothness of relative prices which this regime entails. Over-stabilization of the terms of trade prevents prices from adjusting efficiently in response to shocks and augments the negative impact of nominal rigidities on welfare. This generates a significant deviation from the optimal policy. In other words, CPI targeting represents too general policy regime. It aggregates several welfare-relevant variables (domestic inflation rates and relative prices), prescribing a suboptimal reaction to deviations in these terms. Rule 9, which allows a differentiated response to CPI inflation and exchange rate changes, outperforms strict CPI targeting.

The values of the optimized coefficients $\mathrm{k} 1, \mathrm{k} 2, \mathrm{k} 3$, and $\mathrm{k} 4$ displayed in table 1 provide information about the relative magnitude of the policy response to deviations in key macroeconomic variables. Specifically, the OSRs indicate that the policy should respond more aggressively to variations in the non-traded sector variables (output and inflation rates).

The important criterion for evaluating the performance of the simple rules is the level of macroeconomic stability which they induce. Alternative regimes may gener- 
ate comparable welfare results but, at the same time, imply different volatility of the macroeconomic variables. This issue becomes particularly important prior to entering the Eurozone, when the monetary authority has to fulfill specific and sometimes conflicting stabilization objectives. Table 2 presents the standard deviations of the key variables under different OSRs relative to the standard deviations implied by the optimal policy.

Comparing the volatility under the alternative regimes we note that the rules that strictly target aggregate variables naturally perform the worst in terms of stabilization of the particular economic sectors. Thus, under the DIT, CPI, and PEG regimes, the volatility of the sector-specific variables diverges the most from the deviations implied by the optimal rule. In particular, sectoral inflation rates are $40 \%$ over (for home inflation) or under-stabilized (for non-traded inflation) under the DIT regime. At the same time, the output gap in the home-goods sector is $16 \%$ more volatile relative to its standard deviation under the optimal policy.

The comparison of DIT and the rule that targets the properly weighted domestic inflation index (rule 10) suggests that under the latter, the volatility of sector-specific inflation rates is closer to the optimal values and non-traded inflation is less volatile. Such an outcome reflects the different magnitude of the policy response with respect to the sectoral inflation rates expressed by the optimal values of the parameters $\mathrm{k} 1$ and $\mathrm{k} 2$. In all cases of strict inflation targeting (rules $1,2,6,7,10)$ fulfillment of the inflation objectives comes at the expense of higher than optimal volatility of the output gap, at sector-specific and/or aggregate levels. The rule that stabilizes the traded and nontraded output gaps separately (rule 5) allows the standard deviations of the sectorspecific inflation rates to be brought closer to the optimal values and, at the same time, provides nearly optimal total output gap stabilization. Finally, regimes, which display the features of an open economy, i.e., prescribes a certain degree of exchange rate management, perform very well in terms of relative price stabilization but may imply somewhat higher variation in output and inflation. In particular, for rule 12, an achieved $6.8 \%$ decrease in the standard deviation of the exchange rate results in a $17.6 \%$ increase in the volatility of non-traded output and an $25 \%$ increase in the standard deviation of domestic inflation. At the same time, such an additional macroeconomic volatility is welfare improving. While responding to a change in the relative prices, the policymaker can better account for sector-specific features and bring the volatility of sectoral variables closer to the optimal values (rules 8 and 9; 10 and 12). Rule 11,which targets the non-traded inflation and the change in the exchange rate, achieves better results in sectoral output gaps targeting comparing to rule 10, and also delivers close to optimal stability of aggregate variables, i.e. CPI inflation and total output gap. 
The results of this section demonstrate the tension between the objectives of domestic inflation and real exchange rate stabilization as well as the inflation-output gap policy trade-off common in the literature. We also numerically assess the welfare benefits of differentiating the policy response depending on economic sectors compared to stabilizing aggregate variables. Moreover, we show that the welfare results achieved under the "sector-specific" targeting rules can be replicated by a rules with an appropriate combination of aggregate variables, namely, the total output gap and the exchange rate change. Responding to the open economy terms may facilitate targeting the sector-specific variables and contribute to welfare improvements when the central bank does not have enough information about domestic sectors.

The exercise presented in this section has important practical implications. In particular, it could provide policymakers with a tool for analyzing the relative importance of monetary policy objectives and facilitate the design of a strategy aimed at achieving several competing goals.

\section{Conclusions}

In this paper we analyzed the stabilization objectives of optimal monetary policy in a two-sector small open economy model obtained as a limiting case of a two-country DSGE framework. We assessed the role of general preferences, structural asymmetries, and multiple relative prices in monetary policy design and welfare evaluation. The stabilization objectives derived for our model specification and represented by the loss function display the features of an open economy and reflect a multisectoral economic structure. Specifically, it is shown that social welfare is affected by deviations in inflation rates and output gaps (with sector-specific weights) as well as in relative prices from their target values. Therefore, the micro-founded welfare objective function differs from the ad hoc forms widely assumed in the applied literature. The exposure of one of the domestic sectors to the external environment not only determines the presence of open economy terms in the loss function, but also affects the decomposition of weights between domestic variables. In particular, the sector that is open to trade is allowed to adjust more at the optimum compared to the sector that produces goods for internal consumption only. Such a result implies a qualitatively different magnitude of the response to deviations in sector-specific variables compared to the closed economy setting and determines the asymmetric response of the domestic sectors to various shocks. We characterized the optimal policy by the optimal targeting rule, which is a rather complex expression. 
Finally, we experimented with alternative simple rules and analyzed their ability to replicate the optimal solution. The numerical results suggest that the type of shock is an important determinant of the comparative performance of optimal versus simple policy rules. Specifically, the optimal responses differ the most from the simple rules under fiscal and mark-up shocks. On the contrary, the DIT regime better approximates the optimal plan under foreign and productivity shocks.

An analysis of the welfare implications of alternative simple rules suggests that strict targeting of domestic and CPI inflation does not yield the best approximations for the optimal policy, and social welfare can be improved by accounting for other policy objectives, namely, the output gap and the exchange rate. We presented a ranking of alternative simple rules and evaluated the welfare benefits of targeting sector-specific versus aggregate variables. In addition, we showed that the simple rules which incorporate a response to the relative price changes acheive more efficient stabilization of sector-specific variables. Such a result is important because a strategy which differentiates the response between domestic sectors is difficult to design and implement in practice. Generally, the simple rules perform quite well in terms of macroeconomic stabilization (relative to the optimal rule) and can deliver reasonable welfare results. An analysis of macroeconomic volatility under the simple rules demonstrated that our model generated an endogenous conflict between the objectives of domestic inflation and real exchange rate stabilization in addition to the inflation-output gap policy trade-off common in the literature.

The analysis of optimal monetary policy based on micro-foundations which we employed in this paper enabled us to uncover important effects and incentives that arise in an open multisectoral economy. We were able to provide a welfare analysis based on economic fundamentals. Moreover, alternative simple rules were ranked according to a rigorous (but tractable) welfare measure. At the same time we have to admit that the model lacks inflation inertia and persistence. This is a common disadvantage of the New Keynesian class of models, which have to be augmented with a number of frictions in order to reflect the actual dynamics of inflation and output. Therefore, we restrict our analysis to rather normative conclusions and admit the limited use of such models for forecasting purposes. However, we are convinced that the micro-founded and socalled reduced form approaches should interact in a complementary way in order to provide the appropriate policy recommendations. In fact, a comparative assessment of the monetary policy prescriptions derived in more applied studies versus the optimal reactions based on micro-foundations would be an interesting point for further analysis. 


\section{References}

Aoki, K. (2001). Optimal monetary policy responses to relative price changes. Journal of Monetary Economics 48, 55-80.

Benigno, G. and P. Benigno (2003, October). Price stability in open economies. The Review of Economic Studies.

Benigno, G. and P. Benigno (2006). Designing targeting rules for international monetary policy coordination. Journal of Monetary Economics 53, 473-506.

Benigno, P. and M. Woodford (2005). Inflation stabilization and welfare: The case of large distortions. Journal of the European Economic Association 1, 1-52.

Clarida, R., J. Gali, and M. Gertler (2001). Optimal monetary policy in open versus closed economies. an integrated approach. American Economic Review 91(2).

Corsetti, G. and P. Pesenti (2005). International dimensions of optimal monetary policy. Journal of Monetary Economics 52(2), 281-305.

De Paoli, B. (2006). Optimal monetary policy and welfare in a small open economy. CEP Discussion Papers 639, Centre for Economic Performance, LSE.

Erceg, C. and A. Levin (2006). Optimal monetary policy with durable consumption goods. Journal of Monetary Economics 53, 1341-1359.

Gali, J. and T. Monacelli (2005). Monetary policy and exchange rate volatility in a small open economy. Review of Economic Studies 72(3).

Hlédik, T. (2003). Modelling the second-round effects of supply-side shocks on inflation. CNB Working Paper Series 12, Czech National Bank.

Liu, Z. and E. Pappa (2005). Gains from international monetary policy coordination. does it pay to be different? Working paper, European Central Bank.

Monacelli, T. (2003). Monetary policy in a low pass-through environment. Working Paper 227, European Central Bank.

Soto, C. (2003). Non-traded goods and monetary policy trade-offs in a small open economy. Working Paper 214, Central Bank of Chile.

Sutherland, A. (2002). Incomplete pass-through and the welfare effects of exchange rate variability. Discussion Paper 0212, Department of Economics, University of St. Andrews.

Woodford, M. (2003). Interest and prices: Foundation of a theory of monetary policy. Princeton University Press. 


\section{Appendix}

\subsection{The Steady State}

We approximate the model around the steady state, in which $\bar{A}_{N}=\bar{A}_{H}=1, \bar{G}_{H}=$ $\bar{G}_{N}=0, \bar{\mu}_{H} \geq 1, \bar{\mu}_{N} \geq 1$. We assume that producer prices do not change in the steady state, i.e., $\Pi_{H}=\frac{P_{H, t}}{P_{H, t-1}}=1$ and $\Pi_{N}=\frac{P_{N, t}}{P_{N, t-1}}=1$ at all times. The optimal risk-sharing condition implies that $E R_{t}=\frac{U_{C}\left(C_{t}^{*}\right)}{U_{C}\left(C_{t}\right)} k_{o}$. Under the given functional forms, we obtain the condition for the steady state: $\overline{E R}=\left(\frac{\bar{C}}{\bar{C}^{*}}\right)^{\rho} k_{o}$. By choosing $k_{o}=\left(\frac{\bar{C}}{\bar{C}^{*}}\right)^{-\rho}$ we obtain the steady state real exchange rate equal to unity, i.e., $\overline{E R}=1$. We normalize the price indexes of traded goods at home and abroad so that $\bar{P}_{H}=\bar{P}_{F}$, as usually assumed in the literature, i.e., in the steady state the terms of trade $P_{F H}$ are equal to unity. Moreover, from the price index equation (1a) it follows that $\bar{P}_{H}=\bar{P}_{T}$. We can write the general price index (1) as: $1=\left[\gamma \bar{p}_{N}^{1-\omega}+(1-\gamma) \bar{p}_{T}^{1-\omega}\right]^{\frac{1}{1-\omega}}$ where $\bar{p}_{N}=\frac{\overline{P_{N}}}{\bar{P}}, \bar{p}_{T}=\frac{\overline{P_{T}}}{\bar{P}}$. From this relation we obtain $\bar{P}_{N}=\bar{P}_{T}=\bar{P}$. The price index equations and the fact that $\overline{E R}=1$ imply that in the steady state prices at home and abroad are equalized. Furthermore, the price setting equations imply the following relationships in the steady state:

$$
\begin{gathered}
U_{C}(\bar{C}) \frac{\overline{P_{H}}}{\bar{P}}=\bar{\mu}_{H} V_{y}\left(\bar{Y}_{H}\right), \\
U_{C}(\bar{C}) \frac{\overline{P_{N}}}{\bar{P}}=\bar{\mu}_{N} V_{y}\left(\bar{Y}_{N}\right) .
\end{gathered}
$$

From the aggregate demand equations (7) and (4) (main text) we obtain:

$$
\begin{gathered}
\bar{Y}_{H}=\left[(1-\gamma) v \bar{C}+\left(1-\gamma^{*}\right) \widetilde{v}^{*} \bar{C}^{*}\right] \\
\bar{Y}_{N}=\gamma \bar{C} .
\end{gathered}
$$

The world aggregate resource constraint is given by: $\bar{Y}+\bar{Y}^{*}=\bar{C}+\bar{C}^{*}$. Combining this condition with (3) and (4) we obtain:

$$
\frac{\bar{C}}{\bar{C}^{*}}=\frac{\left(1-\gamma^{*}\right) \widetilde{v}^{*}}{(1-\gamma)(1-v)} .
$$

This relation demonstrates that even under the complete market assumption, the structural asymmetries result in a wedge between consumption in the two countries. Finally, $k_{o}=\left(\frac{\bar{C}}{\bar{C}^{*}}\right)^{-\rho}=\left(\frac{\left(1-\gamma^{*}\right) \widetilde{v}^{*}}{(1-\gamma)(1-v)} \cdot\right)^{-\rho}$. 


\subsection{Second-Order Approximation to the Utility Function and Equilibrium Conditions}

We apply the methodology described in Woodford (2003) and Benigno and Woodford (2005) in order to obtain the second-order approximation to the utility function of the form:

$$
U_{t}^{j}=E_{t}\left\{\sum_{s=t}^{\infty} \beta^{s-t}\left[U\left(C_{s}^{j}\right)-V\left(y_{s, T}(j), A_{s, T}^{i}\right)-V\left(y_{s, N}(j), A_{s, N}^{i}\right)\right]\right\} .
$$

We assume that preferences have isoelastic functional form and we arrive at the following expression:

$$
\begin{aligned}
W_{t o}= & U_{C} \bar{C} E_{t_{0}} \sum_{t=t_{0}}^{\infty} \beta^{t-t_{0}} \times \\
& {\left[\begin{array}{c}
\widehat{C}_{t}-\left(\bar{\mu}_{N}\right)^{-1} \gamma \widehat{Y}_{N, t}-\left(\bar{\mu}_{H}\right)^{-1}(1-\gamma) \widehat{Y}_{H, t}+\frac{1}{2}(1-\rho) \widehat{C}_{t}^{2} \\
-\frac{1}{2}\left(\bar{\mu}_{N}\right)^{-1} \gamma(1+\eta) \widehat{Y}_{N, t}^{2}-\frac{1}{2}\left(\bar{\mu}_{H}\right)^{-1}(1-\gamma)(1+\eta) \widehat{Y}_{H, t}^{2} \\
+\left(\bar{\mu}_{N}\right)^{-1} \gamma \eta \widehat{A}_{N, t} \widehat{Y}_{N, t}+\left(\bar{\mu}_{H}\right)^{-1}(1-\gamma) \eta \widehat{A}_{H, t} \widehat{Y}_{H, t} \\
-\frac{1}{2} \gamma \frac{\sigma}{\bar{\mu}_{N} k_{N}} \pi_{N, t}^{2}-\frac{1}{2}(1-\gamma) \frac{\sigma}{\bar{\mu}_{H} k_{H}} \pi_{H, t}^{2}+t . i \cdot p+\left(\left\|\xi^{3}\right\|\right)
\end{array}\right] }
\end{aligned}
$$

where t.i.p. denotes terms that are independent of policy and $\left(\left\|\xi^{3}\right\|\right)$ denotes terms that are of third order and higher. We can write (7) in a vector-matrix form as:

$W_{t o}=U_{C} \bar{C} E_{t_{0}} \sum_{t=t_{0}}^{\infty} \beta^{t-t_{0}}\left[z_{x}^{\prime} x_{t}-\frac{1}{2} x_{t}^{\prime} Z_{x} x_{t}-x_{t}^{\prime} Z_{\xi} \xi_{t}-\frac{1}{2} z_{\pi_{H}} \pi_{H, t}^{2}-\frac{1}{2} z_{\pi_{N}} \pi_{N, t}^{2}\right]+t . i . p+\left(\left\|\xi^{3}\right\|\right)$

where

$$
\begin{aligned}
& x_{t}^{\prime} \equiv\left[\begin{array}{llllll}
\widehat{Y}_{H, t} & \widehat{Y}_{N, t} & \widehat{C}_{t} & \widehat{P}_{H T, t} & \widehat{P}_{N T, t} & \widehat{E R}_{t}
\end{array}\right], \\
& \xi_{t}^{\prime} \equiv\left[\begin{array}{llllllll}
\widehat{A}_{H, t} & \widehat{A}_{N, t} & \widehat{\mu}_{H, t} & \widehat{\mu}_{N, t} & \widehat{g}_{H, t} & \widehat{g}_{N, t} & \widehat{C}_{t}^{*} & \widehat{P}_{N T, t}^{*}
\end{array}\right], \\
& z_{x}^{\prime} \equiv\left[\begin{array}{llllll}
\left(-\left(\bar{\mu}_{H}\right)^{-1}(1-\gamma)\right) & \left(-\left(\bar{\mu}_{N}\right)^{-1} \gamma\right) & 1 & 0 & 0 & 0
\end{array}\right] \text {, } \\
& Z_{x} \equiv\left[\begin{array}{cccccc}
\left(\bar{\mu}_{H}\right)^{-1}(1-\gamma)(1+\eta) & 0 & 0 & 0 & 0 & 0 \\
0 & \left(\bar{\mu}_{N}\right)^{-1} \gamma(1+\eta) & 0 & 0 & 0 & 0 \\
0 & 0 & -(1-\rho) & 0 & 0 & 0 \\
0 & 0 & 0 & 0 & 0 & 0 \\
0 & 0 & 0 & 0 & 0 & 0 \\
0 & 0 & 0 & 0 & 0 & 0
\end{array}\right]
\end{aligned}
$$




$$
\begin{aligned}
& Z_{\xi} \equiv\left[\begin{array}{cccccccc}
-\left(\bar{\mu}_{H}\right)^{-1}(1-\gamma) \eta & 0 & 0 & 0 & 0 & 0 & 0 & 0 \\
0 & -\left(\bar{\mu}_{N}\right)^{-1} \gamma \eta & 0 & 0 & 0 & 0 & 0 & 0 \\
0 & 0 & 0 & 0 & 0 & 0 & 0 & 0 \\
0 & 0 & 0 & 0 & 0 & 0 & 0 & 0 \\
0 & 0 & 0 & 0 & 0 & 0 & 0 & 0 \\
0 & 0 & 0 & 0 & 0 & 0 & 0 & 0
\end{array}\right] \\
& z_{\pi_{H}} \equiv(1-\gamma) \frac{\sigma}{\bar{\mu}_{H} k_{H}} \quad z_{\pi_{N}} \equiv \gamma \frac{\sigma}{\bar{\mu}_{N} k_{N}},
\end{aligned}
$$

where $k_{L}=\frac{\left(1-\alpha_{L} \beta\right)\left(1-\alpha_{L}\right)}{\alpha_{L}(1+\sigma \eta)}$, for $L=H, N$.

We now derive the second-order approximation to the structural equilibrium conditions. Following Benigno and Woodford (2005), we approximate the optimal pricesetting equation (expression (10) in the main text) for both domestic sectors as well as the law of motion for the sectoral price indices (11). We combine the corresponding expressions and, after integrating forward, obtain the following relations:

$$
\begin{aligned}
& V_{0}^{H}=E_{t_{0}} \sum_{t=t_{0}}^{\infty} \beta^{t-t_{0}} \times \\
& \left\{\begin{array}{l}
{\left[\eta \widehat{Y}_{H, t}+\rho \widehat{C}_{t}-\widehat{P}_{H T, t}+\gamma \widehat{P}_{N T, t}+\widehat{\mu}_{H, t}-\eta \widehat{A}_{H, t}\right]+\frac{1}{2} \gamma(1-\omega)(1-\gamma) \widehat{P}_{N T, t}^{2}} \\
+\frac{1}{2}\left[\begin{array}{c}
\eta \widehat{Y}_{H, t}+\rho \widehat{C}_{t}-\widehat{P}_{H T, t}+ \\
\gamma \widehat{P}_{N T, t}+\widehat{\mu}_{H, t}-\eta \widehat{A}_{H, t}
\end{array}\right] \times\left[\begin{array}{c}
(2+\eta) \widehat{Y}_{H, t}-\rho \widehat{C}_{t}+\widehat{P}_{H T, t}- \\
\gamma \widehat{P}_{N T, t}+\widehat{\mu}_{H, t}-\eta \widehat{A}_{H, t}
\end{array}\right] \\
+\frac{1}{2} \frac{\sigma(1+\eta)}{k_{H}} \pi_{H, t}^{2}+\text { s.o.t.i.p. }+\left(\left\|\xi^{3}\right\|\right)
\end{array}\right\} \\
& V_{0}^{N}=E_{t_{0}} \sum_{t=t_{0}}^{\infty} \beta^{t-t_{0}} \times \\
& \left\{\begin{array}{c}
{\left[\eta \widehat{Y}_{N, t}+\rho \widehat{C}_{t}-(1-\gamma) \widehat{P}_{N T, t}+\widehat{\mu}_{N, t}-\eta \widehat{A}_{N, t}\right]++\frac{1}{2} \gamma(1-\omega)(1-\gamma) \widehat{P}_{N T, t}^{2}} \\
+\frac{1}{2}\left[\begin{array}{c}
\eta \widehat{Y}_{N, t}+\rho \widehat{C}_{t}-(1-\gamma) \widehat{P}_{N T, t}+ \\
\widehat{\mu}_{N, t}-\eta \widehat{A}_{N, t}
\end{array}\right] \times\left[\begin{array}{c}
(2+\eta) \widehat{Y}_{N, t}-\rho \widehat{C}_{t}+(1-\gamma) \widehat{P}_{N T, t}+ \\
+\widehat{\mu}_{N, t}-\eta \widehat{A}_{N, t}
\end{array}\right] \\
+\frac{1}{2} \frac{\sigma(1+\eta)}{k_{N}} \pi_{N, t}^{2}+\text { s.o.t.i.p. }+\left(\left\|\xi^{3}\right\|\right)
\end{array}\right\},
\end{aligned}
$$

where s.o.t.i.p. denotes second-order terms independent of policy. We can present equations (9) and (10) in a vector-matrix form as :

$V_{0}^{H}=E_{t_{0}} \sum_{t=t_{0}}^{\infty} \beta^{t-t_{0}}\left[a_{x}^{\prime} x_{t}+a_{\xi}^{\prime} \xi_{t}+\frac{1}{2} x_{t}^{\prime} A_{x} x_{t}+x_{t}^{\prime} A_{\xi} \xi_{t}+\frac{1}{2} a_{\pi_{H}} \pi_{H, t}^{2}\right]+$ s.o.t.i.p. $+\left(\left\|\xi^{3}\right\|\right)$ 


$$
V_{0}^{N}=E_{t_{0}} \sum_{t=t_{0}}^{\infty} \beta^{t-t_{0}}\left[b_{x}^{\prime} x_{t}+b_{\xi}^{\prime} \xi_{t}+\frac{1}{2} x_{t}^{\prime} B_{x} x_{t}+x_{t}^{\prime} B_{\xi} \xi_{t}+\frac{1}{2} b_{\pi_{N}} \pi_{N, t}^{2}\right]+\text { s.o.t.i.p. }+\left(\left\|\xi^{3}\right\|\right)
$$

where

$$
\begin{aligned}
& a_{x}^{\prime} \equiv\left[\begin{array}{llllll}
\eta & 0 & \rho & -1 & \gamma & 0
\end{array}\right], \\
& a_{\xi}^{\prime} \equiv\left[\begin{array}{llllllll}
-\eta & 0 & 1 & 0 & 0 & 0 & 0 & 0
\end{array}\right] \text {. } \\
& A_{x} \equiv\left[\begin{array}{cccccc}
\eta(2+\eta) & 0 & \rho & -1 & \gamma & 0 \\
0 & 0 & 0 & 0 & 0 & 0 \\
\rho & 0 & -\rho^{2} & \rho & \rho \gamma & 0 \\
-1 & 0 & \rho & -1 & \gamma & 0 \\
\gamma & 0 & \rho \gamma & \gamma & -\gamma^{2} & 0 \\
0 & 0 & 0 & 0 & 0 & 0
\end{array}\right] \\
& A_{\xi} \equiv\left[\begin{array}{cccccccc}
-\eta(1+\eta) & 0 & (1+\eta) & 0 & 0 & 0 & 0 & 0 \\
0 & 0 & 0 & 0 & 0 & 0 & 0 & 0 \\
0 & 0 & 0 & 0 & 0 & 0 & 0 & 0 \\
0 & 0 & 0 & 0 & 0 & 0 & 0 & 0 \\
0 & 0 & 0 & 0 & 0 & 0 & 0 & 0 \\
0 & 0 & 0 & 0 & 0 & 0 & 0 & 0
\end{array}\right] \\
& a_{\pi_{H}} \equiv \frac{\sigma(1+\eta)}{k_{H}} \\
& b_{x}^{\prime} \equiv\left[\begin{array}{llllll}
0 & \eta & \rho & 0 & -(1-\gamma) & 0
\end{array}\right], \\
& b_{\xi}^{\prime} \equiv\left[\begin{array}{llllllll}
0 & -\eta & 0 & 1 & 0 & 0 & 0 & 0
\end{array}\right] \text {. } \\
& B_{x} \equiv\left[\begin{array}{cccccc}
0 & 0 & 0 & 0 & 0 & 0 \\
0 & \eta(2+\eta) & \rho & 0 & -(1-\gamma) & 0 \\
0 & \rho & -\rho^{2} & 0 & \rho(1-\gamma) & 0 \\
0 & 0 & 0 & 0 & 0 & 0 \\
0 & -(1-\gamma) & \rho(1-\gamma) & 0 & (1-\gamma)^{2} & 0 \\
0 & 0 & 0 & 0 & 0 & 0
\end{array}\right] \text {, }
\end{aligned}
$$




$$
\begin{aligned}
B_{\xi} \equiv & {\left[\begin{array}{cccccccc}
0 & 0 & 0 & 0 & 0 & 0 & 0 & 0 \\
0 & -\eta(1+\eta) & 0 & (1+\eta) & 0 & 0 & 0 & 0 \\
0 & 0 & 0 & 0 & 0 & 0 & 0 & 0 \\
0 & 0 & 0 & 0 & 0 & 0 & 0 & 0 \\
0 & 0 & 0 & 0 & 0 & 0 & 0 & 0 \\
0 & 0 & 0 & 0 & 0 & 0 & 0 & 0
\end{array}\right] ; } \\
& b_{\pi_{N}} \equiv \frac{\sigma(1+\eta)}{k_{N}} .
\end{aligned}
$$

The traded-goods demand equation is of the form:

$$
\begin{aligned}
Y_{H} & =\left(\frac{P_{T}}{P}\right)^{-\omega}\left(\frac{P_{H}}{P_{T}}\right)^{-\theta} \times \\
& \left\{v(1-\gamma) C+\left(\frac{1}{E R}\right)^{-\omega}\left[\left(\frac{1}{v\left(P_{F H}\right)^{\theta-1}+(1-v)}\right)\right]^{\frac{\theta-\omega}{1-\theta}}\left(1-\gamma^{*}\right) \widetilde{v}^{*} C^{*}\right\} .
\end{aligned}
$$

We take the second-order expansion of (13) and obtain the following relation:

$$
\begin{aligned}
\widehat{Y}_{H, t}= & -[\theta+(\theta-\omega) v] \widehat{P}_{H T, t}+\omega \gamma \widehat{P}_{N T, t}+v \widehat{C}_{t}+\omega(1-v) \widehat{E R}_{t}+(1-v) \widehat{C}_{t}^{*}+ \\
& +\widehat{g}_{H, t}+\frac{1}{2} v(1-v) \widehat{C}_{t}^{2}+\frac{1}{2} \omega^{2} v(1-v) \widehat{E R}_{t}^{2}+\frac{1}{2} \omega(1-\omega) \gamma(1-\gamma) \widehat{P}_{N T, t}- \\
& -\frac{1}{2} \frac{v}{(1-v)}\left[(1-\theta)(\theta-\omega)-(\theta-\omega)^{2} v^{2}\right] \widehat{P}_{H T, t}^{2}-(\theta-\omega) \omega v^{2} \widehat{E R}_{t} \widehat{P}_{H T, t}- \\
& -\omega v(1-v) \widehat{E R}_{t} \widehat{C}_{t}+(\theta-\omega) v^{2} \widehat{C}_{t} \widehat{P}_{H T, t}+\omega v(1-v) \widehat{E R}_{t} \widehat{C}_{t}^{*}-(\theta-\omega) v^{2} \widehat{P}_{H T, t} \widehat{C}_{t}^{*}- \\
& -v(1-v) \widehat{C}_{t} \widehat{C}_{t}^{*}-\omega \gamma \widehat{P}_{N T, t} \widehat{g}_{H, t}+[\theta+v(\theta-\omega)] \widehat{P}_{H T, t} \widehat{g}_{H, t}-v \widehat{C}_{t} \widehat{g}_{H, t}- \\
& -\omega(1-v) \widehat{E R}_{t} \widehat{g}_{H, t}+\text { s.o.t.i.p. }+\left(\left\|\xi^{3}\right\|\right) .
\end{aligned}
$$

In a vector-matrix form the expression above takes the following form:

$$
\sum_{t=t_{0}}^{\infty} \beta^{t-t_{0}}\left[c_{x}^{\prime} x_{t}+c_{\xi}^{\prime} \xi_{t}+\frac{1}{2} x_{t}^{\prime} C_{x} x_{t}+x_{t}^{\prime} C_{\xi} \xi_{t}\right]+\text { s.o.t.i.p. }+\left(\left\|\xi^{3}\right\|\right)=0
$$

where

$$
\begin{gathered}
c_{x}^{\prime} \equiv\left[\begin{array}{ccccccc}
-1 & 0 & v & -[\theta+(\theta-\omega) v] & \omega \gamma & \omega(1-v)
\end{array}\right], \\
c_{\xi}^{\prime} \equiv\left[\begin{array}{llllllll}
0 & 0 & 0 & 0 & 1 & 0 & (1-v) & 0
\end{array}\right] .
\end{gathered}
$$




$$
\begin{aligned}
& C_{x} \equiv\left[\begin{array}{cccccc}
0 & 0 & 0 & 0 & 0 & 0 \\
0 & 0 & 0 & 0 & 0 & 0 \\
0 & 0 & v(1-v) & (\theta-\omega) v^{2} & 0 & -\omega v(1-v) \\
0 & 0 & (\theta-\omega) v^{2} & \frac{v}{(1-v)}\left[\begin{array}{c}
(1-\theta)(\theta-\omega)- \\
(\theta-\omega)^{2} v^{2}
\end{array}\right] & 0 & -(\theta-\omega) \omega v^{2} \\
0 & 0 & 0 & 0 & \omega(1-\omega) \gamma(1-\gamma) & 0 \\
0 & 0 & -\omega v(1-v) & -(\theta-\omega) \omega v^{2} & 0 & \omega^{2} v(1-v)
\end{array}\right] \\
& C_{\xi} \equiv\left[\begin{array}{cccccccc}
0 & 0 & 0 & 0 & 0 & 0 & 0 & 0 \\
0 & 0 & 0 & 0 & 0 & 0 & 0 & 0 \\
0 & 0 & 0 & 0 & -v & 0 & -v(1-v) & 0 \\
0 & 0 & 0 & 0 & {[\theta+v(\theta-\omega)]} & 0 & -(\theta-\omega) v^{2} & 0 \\
0 & 0 & 0 & 0 & -\omega \gamma & 0 & 0 & 0 \\
0 & 0 & 0 & 0 & -\omega(1-v) & 0 & \omega v(1-v) & 0
\end{array}\right] .
\end{aligned}
$$

Similarly, the demand equation for non-traded goods takes the following form:

$$
Y_{N}=\left(\frac{P_{N}}{P}\right)^{-\omega} \gamma C
$$

The second-order approximation of this equation yields the following expressions:

$$
\begin{aligned}
& \widehat{Y}_{N, t}=\widehat{C}_{t}-w(1-\gamma) \widehat{P}_{N T, t}+\widehat{g}_{N, t}+\frac{1}{2}(1-\gamma) \gamma \omega(1-\omega) \widehat{P}_{N T, t}^{2}- \\
& \widehat{C}_{t} \widehat{g}_{N, t}+\omega(1-\gamma) \widehat{P}_{N T, t} \widehat{g}_{N, t}+\left(\left\|\xi^{3}\right\|\right), \\
& \sum_{t=t_{0}}^{\infty} \beta^{t-t_{0}}\left[d_{x}^{\prime} x_{t}+d_{\xi}^{\prime} \xi_{t}+\frac{1}{2} x_{t}^{\prime} D_{x} x_{t}+x_{t}^{\prime} D_{\xi} \xi_{t}\right]+\text { s.o.t.i.p. }+\left(\left\|\xi^{3}\right\|\right)=0 . \\
& d_{x}^{\prime} \equiv\left[\begin{array}{llllll}
0 & -1 & 1 & 0 & -w(1-\gamma) & 0
\end{array}\right], \\
& d_{\xi}^{\prime} \equiv\left[\begin{array}{llllllll}
0 & 0 & 0 & 0 & 0 & 1 & 0 & 0
\end{array}\right] \text {, } \\
& D_{x} \equiv\left[\begin{array}{cccccc}
0 & 0 & 0 & 0 & 0 & 0 \\
0 & 0 & 0 & 0 & 0 & 0 \\
0 & 0 & 0 & 0 & 0 & 0 \\
0 & 0 & 0 & 0 & 0 & 0 \\
0 & 0 & 0 & 0 & (1-\gamma) \gamma \omega(1-\omega) & 0 \\
0 & 0 & 0 & 0 & 0 & 0
\end{array}\right]
\end{aligned}
$$




$$
D_{\xi} \equiv\left[\begin{array}{cccccccc}
0 & 0 & 0 & 0 & 0 & 0 & 0 & 0 \\
0 & 0 & 0 & 0 & 0 & 0 & 0 & 0 \\
0 & 0 & 0 & 0 & 0 & -1 & 0 & 0 \\
0 & 0 & 0 & 0 & 0 & 0 & 0 & 0 \\
0 & 0 & 0 & 0 & 0 & \omega(1-\gamma) & 0 & 0 \\
0 & 0 & 0 & 0 & 0 & 0 & 0 & 0
\end{array}\right]
$$

The second-order approximation of the risk-sharing equation (9) in the main text takes the form:

$$
\begin{gathered}
\widehat{C}_{t}=\frac{1}{\rho} \widehat{E R}_{t}+\widehat{C}_{t}^{*} . \\
\sum_{t=t_{0}}^{\infty} \beta^{t-t_{0}}\left[e_{x}^{\prime} x_{t}+e_{\xi}^{\prime} \xi_{t}+\frac{1}{2} x_{t}^{\prime} E_{x} x_{t}+x_{t}^{\prime} E_{\xi} \xi_{t}\right]+\text { s.o.t.i.p. }+\left(\left\|\xi^{3}\right\|\right)=0 . \\
e_{x}^{\prime} \equiv\left[\begin{array}{llllll}
0 & 0 & -1 & 0 & 0 & \frac{1}{\rho}
\end{array}\right] \\
e_{\xi}^{\prime} \equiv\left[\begin{array}{llllllll}
0 & 0 & 0 & 0 & 0 & 0 & 1 & 0
\end{array}\right] \\
E_{x}=0 ; \quad E_{\xi}=0 .
\end{gathered}
$$

Finally, the real exchange rate equation (12) approximated up to the second order takes the form:

$$
\begin{aligned}
& v \widehat{P}_{H T, t}=-(1-v) \widehat{E R}_{t}-\gamma(1-v) \widehat{P}_{N T, t}+\gamma^{*}(1-v) \widehat{P}_{N T, t}^{*}-\frac{1}{2} \frac{(1-v)}{v}(1-\theta) \widehat{E R}_{t}^{2}- \\
& -\frac{1}{2} \gamma(1-v)\left[\frac{\gamma(1-\theta)}{v}+(1-\omega)(1-\gamma)\right] \widehat{P}_{N T, t}^{2}-\frac{\gamma(1-v)}{v}(1-\theta) \widehat{E R}_{t} \widehat{P}_{N T, t}+ \\
& +\frac{(1-v)}{v}(1-\theta) \gamma^{*} \widehat{E R}_{t} \widehat{P}_{N T, t}^{*}+\frac{(1-v)}{v}(1-\theta) \gamma \gamma^{*} \widehat{P}_{N T, t} \widehat{P}_{N T, t}^{*}+\text { s.o.t.i.p. }+\left(\left\|\xi^{3}\right\|\right) \text {. } \\
& \sum_{t=t_{0}}^{\infty} \beta^{t-t_{0}}\left[f_{x}^{\prime} x_{t}+f_{\xi}^{\prime} \xi_{t}+\frac{1}{2} x_{t}^{\prime} F_{x} x_{t}+x_{t}^{\prime} F_{\xi} \xi_{t}\right]+\text { s.o.t.i.p. }+\left(\left\|\xi^{3}\right\|\right)=0 . \\
& f_{x}^{\prime} \equiv\left[\begin{array}{llllll}
0 & 0 & 0 & -v & -\gamma(1-v) & -(1-v)
\end{array}\right] \\
& f_{\xi}^{\prime} \equiv\left[\begin{array}{llllllll}
0 & 0 & 0 & 0 & 0 & 0 & 0 & \gamma^{*}(1-v)
\end{array}\right]
\end{aligned}
$$




$$
\begin{aligned}
& F_{x} \equiv\left[\begin{array}{cccccc}
0 & 0 & 0 & 0 & 0 & 0 \\
0 & 0 & 0 & 0 & 0 & 0 \\
0 & 0 & 0 & 0 & 0 & 0 \\
0 & 0 & 0 & 0 & 0 & 0 \\
0 & 0 & 0 & 0 & -\gamma(1-v)\left[\frac{\gamma(1-\theta)}{v}+(1-\omega)(1-\gamma)\right] & -\frac{\gamma(1-v)}{v}(1-\theta) \\
0 & 0 & 0 & 0 & -\frac{\gamma(1-v)}{v}(1-\theta) & -\frac{(1-v)}{v}(1-\theta)
\end{array}\right], \\
& F_{\xi} \equiv\left[\begin{array}{cccccccc}
0 & 0 & 0 & 0 & 0 & 0 & 0 & 0 \\
0 & 0 & 0 & 0 & 0 & 0 & 0 & 0 \\
0 & 0 & 0 & 0 & 0 & 0 & 0 & 0 \\
0 & 0 & 0 & 0 & 0 & 0 & 0 & 0 \\
0 & 0 & 0 & 0 & 0 & 0 & 0 & \frac{(1-v)}{v}(1-\theta) \gamma \gamma^{*} \\
0 & 0 & 0 & 0 & 0 & 0 & 0 & \frac{(1-v)}{v}(1-\theta) \gamma^{*}
\end{array}\right]
\end{aligned}
$$

We combine constraints (11), (12), (15), (18), (20), and (22) in order to get rid of the linear terms in the objective function (8). We collect vectors that contain the linear components of the above constraints and derive the vector $\lambda$, such that:

$$
\left[\begin{array}{llllll}
a_{x} & b_{x} & c_{x} & d_{x} & e_{x} & f_{x}
\end{array}\right] \times \lambda=z_{x}
$$

We solve the system of linear equations using the symbolic Matlab toolbox and derive values $\lambda_{1}-\lambda_{6}$ associated with each of the constraints. After the linear terms cancel, we obtain the following expression for the loss function:

$L_{t o}=U_{C} \bar{C} E_{t_{0}} \sum_{t=t_{0}}^{\infty} \beta^{t-t_{0}}\left[\frac{1}{2} x_{t}^{\prime} \widetilde{Z}_{x} x_{t}+x_{t}^{\prime} \widetilde{Z}_{\xi} \xi_{t}+\frac{1}{2} \widetilde{Z}_{\pi_{H}} \pi_{H, t}^{2}+\frac{1}{2} \widetilde{Z}_{\pi_{N}} \pi_{N, t}^{2}\right]+K_{0}+$ t.i.p+( $\left.\left\|\xi^{3}\right\|\right)$,

where

$$
\begin{gathered}
\widetilde{Z}_{x}=Z_{x}+\lambda_{1} A_{x}+\lambda_{2} B_{x}+\lambda_{3} C_{x}+\lambda_{4} D_{x}+\lambda_{5} E_{x}+\lambda_{6} F_{x}, \\
\widetilde{Z}_{\xi}=Z_{\xi}+\lambda_{1} A_{\xi}+\lambda_{2} B_{\xi}+\lambda_{3} C_{\xi}+\lambda_{4} D_{\xi}+\lambda_{5} E_{\xi}+\lambda_{6} F_{\xi}, \\
\widetilde{Z}_{\pi_{H}}=z_{\pi_{H}}+\lambda_{1} a_{\pi_{H}}, \\
\widetilde{Z}_{\pi_{N}}=z_{\pi_{N}}+\lambda_{2} b_{\pi_{N}}, \\
K_{0} \equiv U_{C} \bar{C}\left[\lambda_{1} V_{0}^{H}+\lambda_{2} V_{0}^{N}\right] .
\end{gathered}
$$

Vectors $\widetilde{Z}_{x}, \widetilde{Z}_{\pi_{H}}, \widetilde{Z}_{\pi_{N}}$ represent the weights next to the endogenous variables in the objective function.

Furthermore, we would like to present the loss function (23) in terms of the variables 
$\widehat{Y}_{N, t}, \widehat{Y}_{H, t}, \widehat{E R}_{t}, \widehat{P}_{N T, t}$. Thus, we map the vector of all endogenous variables $x_{t}^{\prime} \equiv$ $\left[\begin{array}{llllll}\widehat{Y}_{H, t} & \widehat{Y}_{N, t} & \widehat{C}_{t} & \widehat{P}_{H T, t} & \widehat{P}_{N T, t} & \widehat{E R}_{t}\end{array}\right]$ into the variables of interest with the use of matrices $Q$ and $Q_{\xi}$ such that:

$$
x_{t}=Q\left[\begin{array}{llll}
\widehat{Y}_{H, t} & \widehat{Y}_{N, t} & \widehat{P}_{N T, t} & \widehat{E R}_{t}
\end{array}\right]^{\prime}+Q_{\xi} \xi_{t},
$$

and

$$
\begin{aligned}
& Q=\left[\begin{array}{cccc}
1 & 0 & 0 & 0 \\
0 & 1 & 0 & 0 \\
(1-\gamma) & \gamma & \frac{-\gamma(1-\gamma)(\widetilde{l}+1-v)}{\rho v} & \frac{-(1-\gamma)(l+1-v)}{\rho v} \\
0 & 0 & \frac{-\gamma(1-v)}{v} & \frac{-(1-v)}{v} \\
0 & 0 & 1 & 0 \\
0 & 0 & 0 & 1
\end{array}\right], \\
& Q_{\xi}=\left[\begin{array}{cccccccc}
0 & 0 & 0 & 0 & 0 & 0 & 0 & 0 \\
0 & 0 & 0 & 0 & 0 & 0 & 0 & 0 \\
0 & 0 & 0 & 0 & -(1-\gamma) & -\gamma & 0 & \frac{\gamma^{*}(1-\gamma)(\widetilde{l}+1-v)}{\rho v} \\
0 & 0 & 0 & 0 & 0 & 0 & 0 & \frac{\gamma^{*}(1-v)}{v} \\
0 & 0 & 0 & 0 & 0 & 0 & 0 & 0 \\
0 & 0 & 0 & 0 & 0 & 0 & 0 & 0
\end{array}\right],
\end{aligned}
$$

where $l=(\rho \theta-1)(1-v)(1+v)$ and $\widetilde{l}=l-(\rho \omega-1)(1-v) v$. Therefore, the loss function (23) can be expressed as follows:

$L_{t o}=U_{C} \bar{C} E_{t_{0}} \sum_{t=t_{0}}^{\infty} \beta^{t-t_{0}}\left[\frac{1}{2} X_{t}^{\prime} W_{x} X_{t}+X_{t}^{\prime} W_{\xi} \xi_{t}+\frac{1}{2} W_{\pi_{H}} \pi_{H, t}^{2}+\frac{1}{2} W_{\pi_{N}} \pi_{N, t}^{2}\right]+K_{0}+t . i \cdot p+\left(\left\|\xi^{3}\right\|\right)$,

where $X_{t}^{\prime}=\left[\begin{array}{llll}\widehat{Y}_{H, t} & \widehat{Y}_{N, t} & \widehat{P}_{N T, t} & \widehat{E R}_{t}\end{array}\right], \quad W_{x}=Q^{\prime} \widetilde{Z}_{x} Q, \quad W_{\xi}=Q^{\prime} \widetilde{Z}_{x} Q_{\xi}+Q^{\prime} \widetilde{Z}_{\xi}$, $W_{\pi_{H}}=\widetilde{Z}_{\pi_{H}}, W_{\pi_{N}}=\widetilde{Z}_{\pi_{N}}$.

Finally, we present the variables in the objective function in terms of the deviations from their target values. Thus, we denote the gap as $\widetilde{X}_{t}=\left(X_{t}-X_{t}^{T}\right)$. The target values are functions of the exogenous shocks and take the following general form: $X_{t}^{T}=$ $\left(-\frac{W_{\xi}}{W_{x}} \xi_{t}\right)$. As a result, we are able to present the objective function in the following quadratic form:

$$
\begin{aligned}
L_{t o}= & U_{C} \bar{C} E_{t_{0}} \sum_{t=t_{0}}^{\infty} \beta^{t-t_{0}}\left[\frac{1}{2}\left(X_{t}-X_{t}^{T}\right)^{\prime} W_{x}\left(X_{t}-X_{t}^{T}\right)+\frac{1}{2} W_{\pi_{H}} \pi_{H, t}^{2}+\frac{1}{2} W_{\pi_{N}} \pi_{N, t}^{2}\right]+ \\
& +K_{0}+t . i . p+\left(\left\|\xi^{3}\right\|\right) .
\end{aligned}
$$


Expression (26) corresponds to formula (29) in the main text.

\subsection{Tables and Figures}




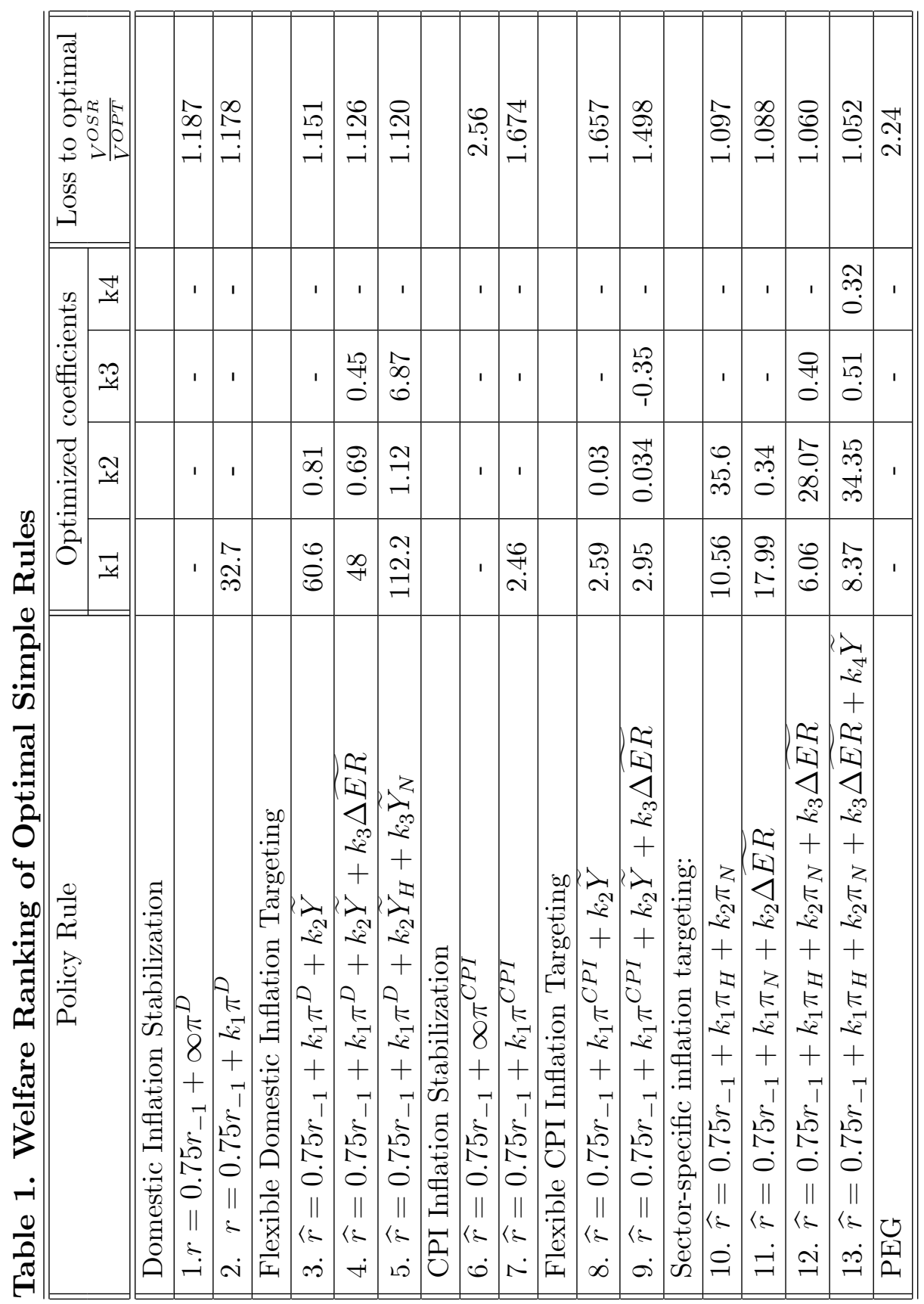




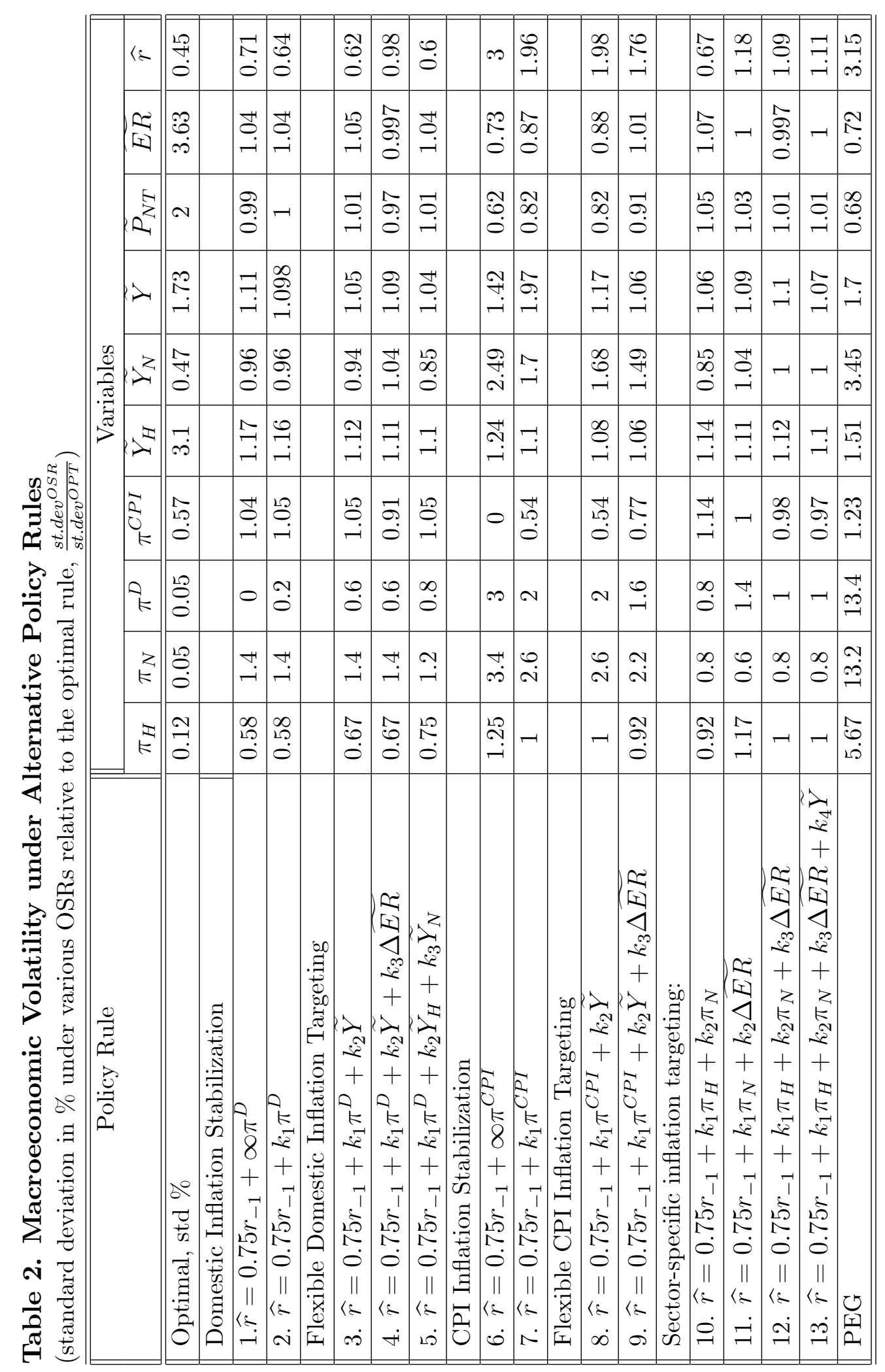




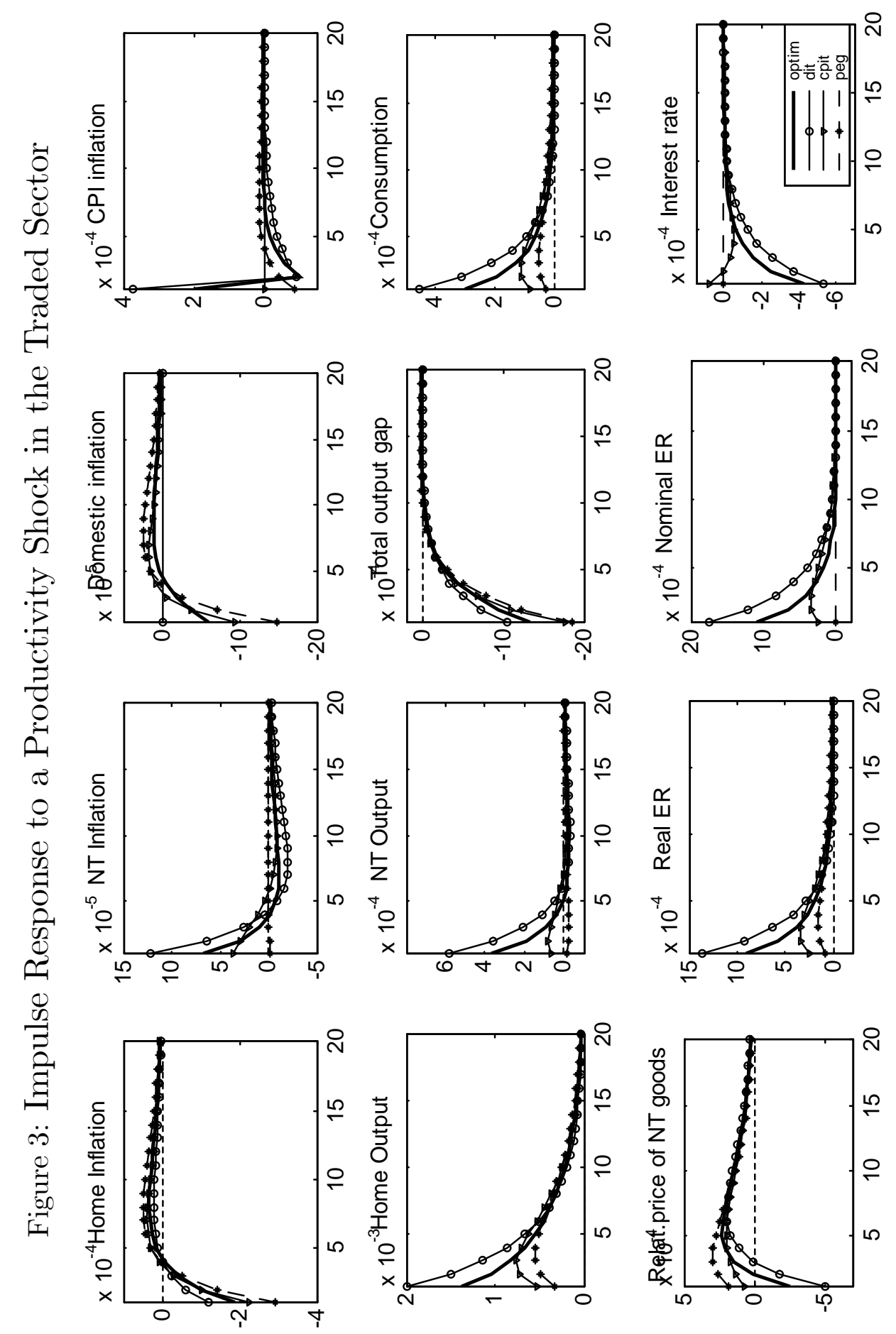




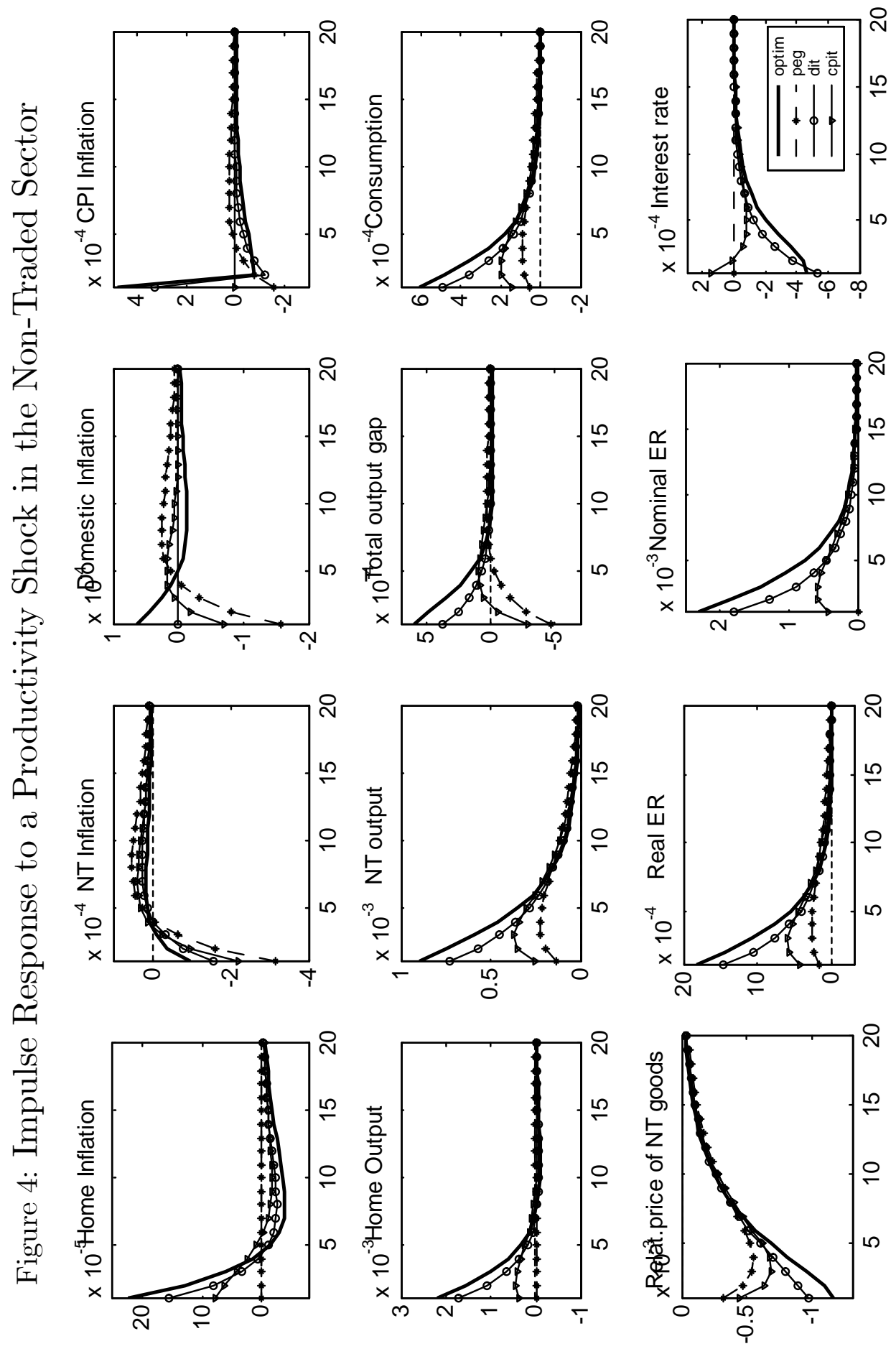




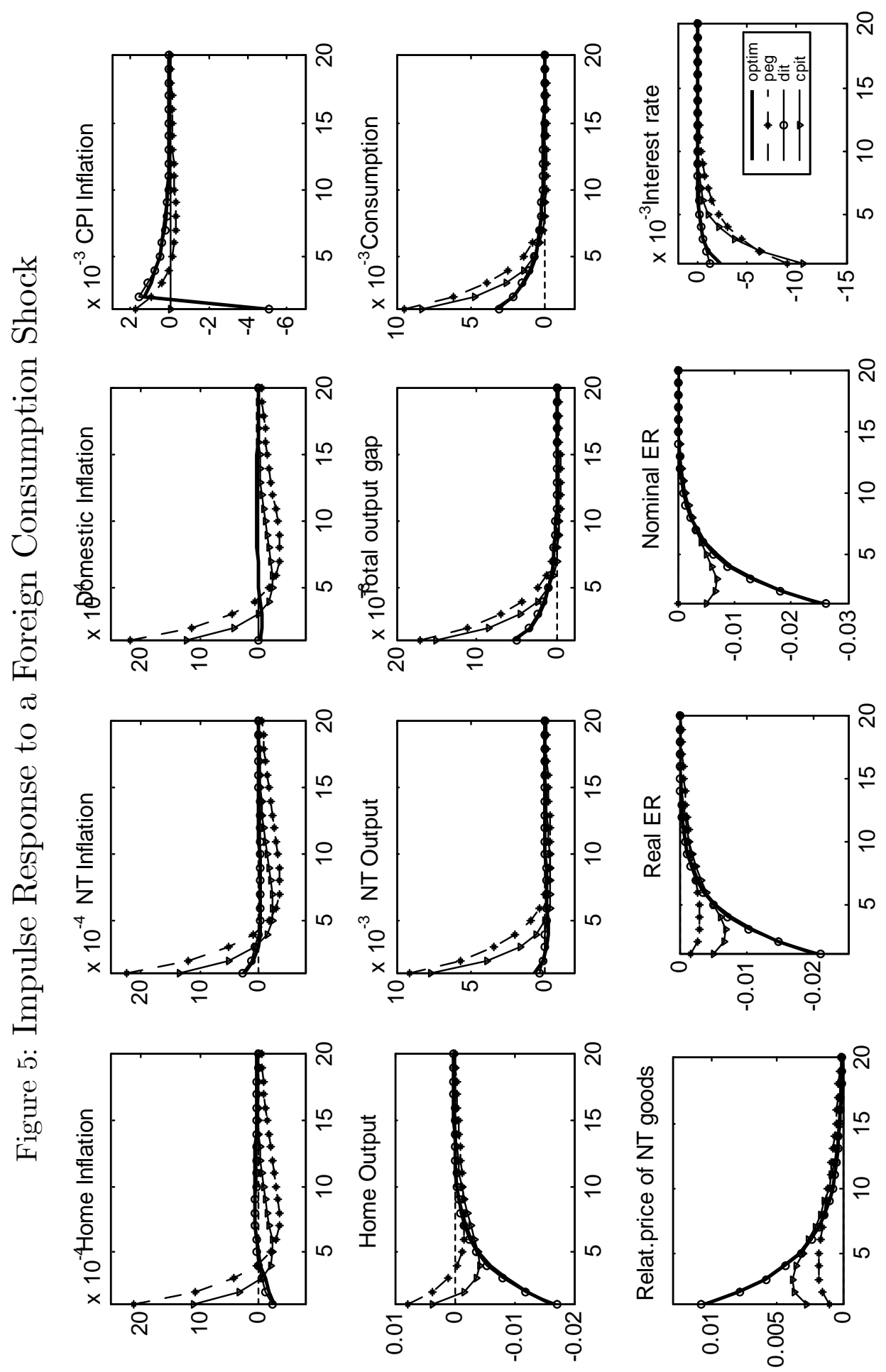




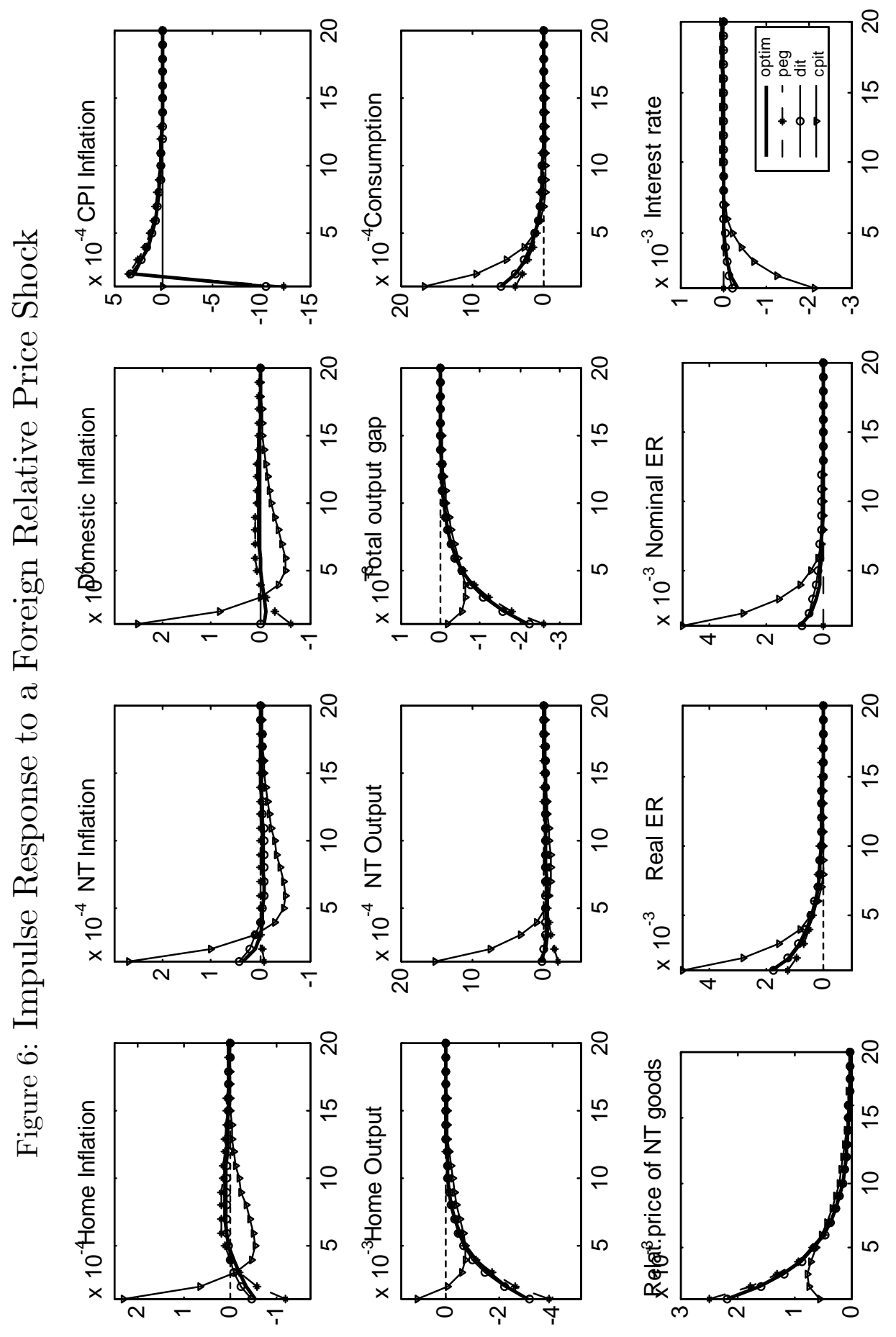




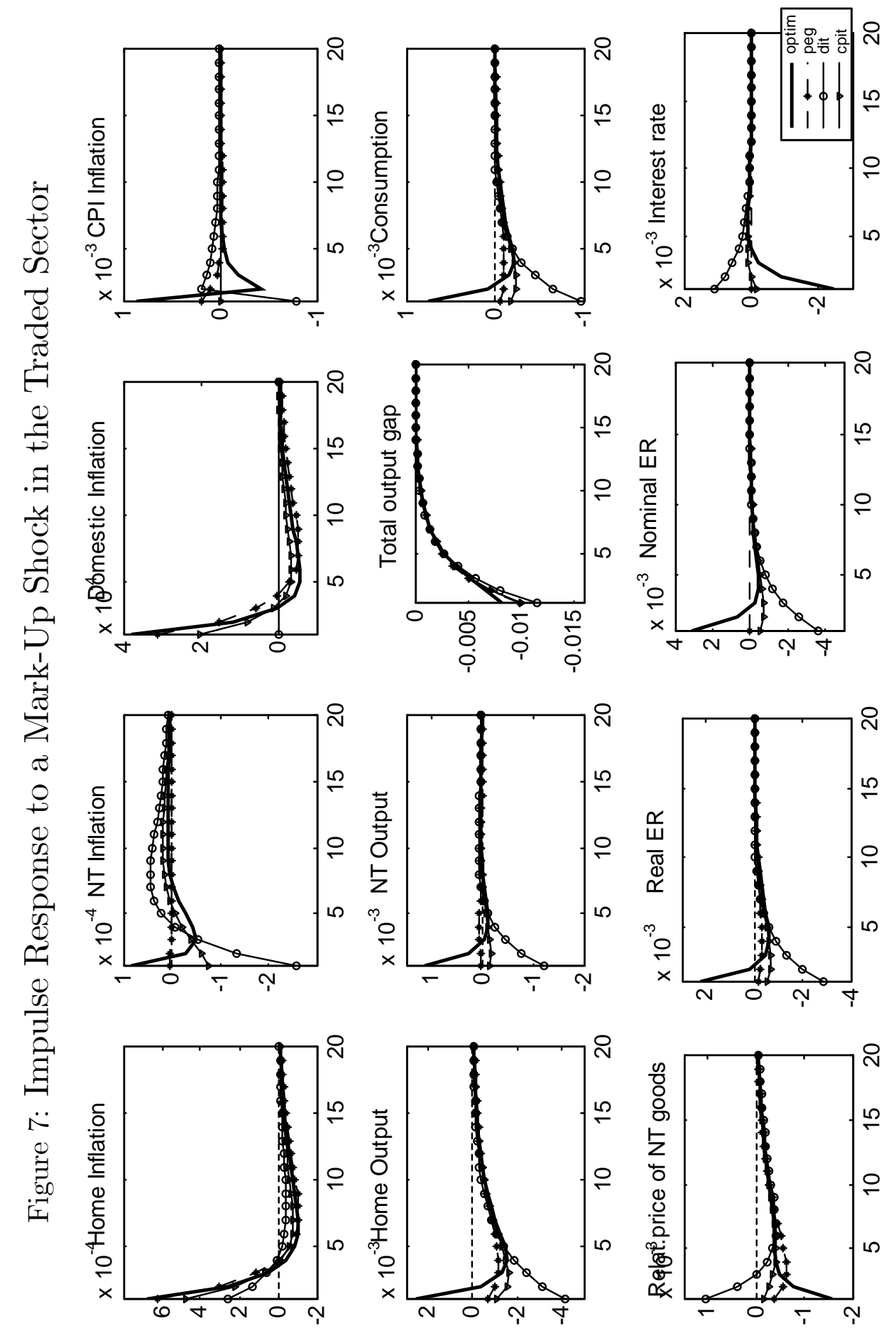




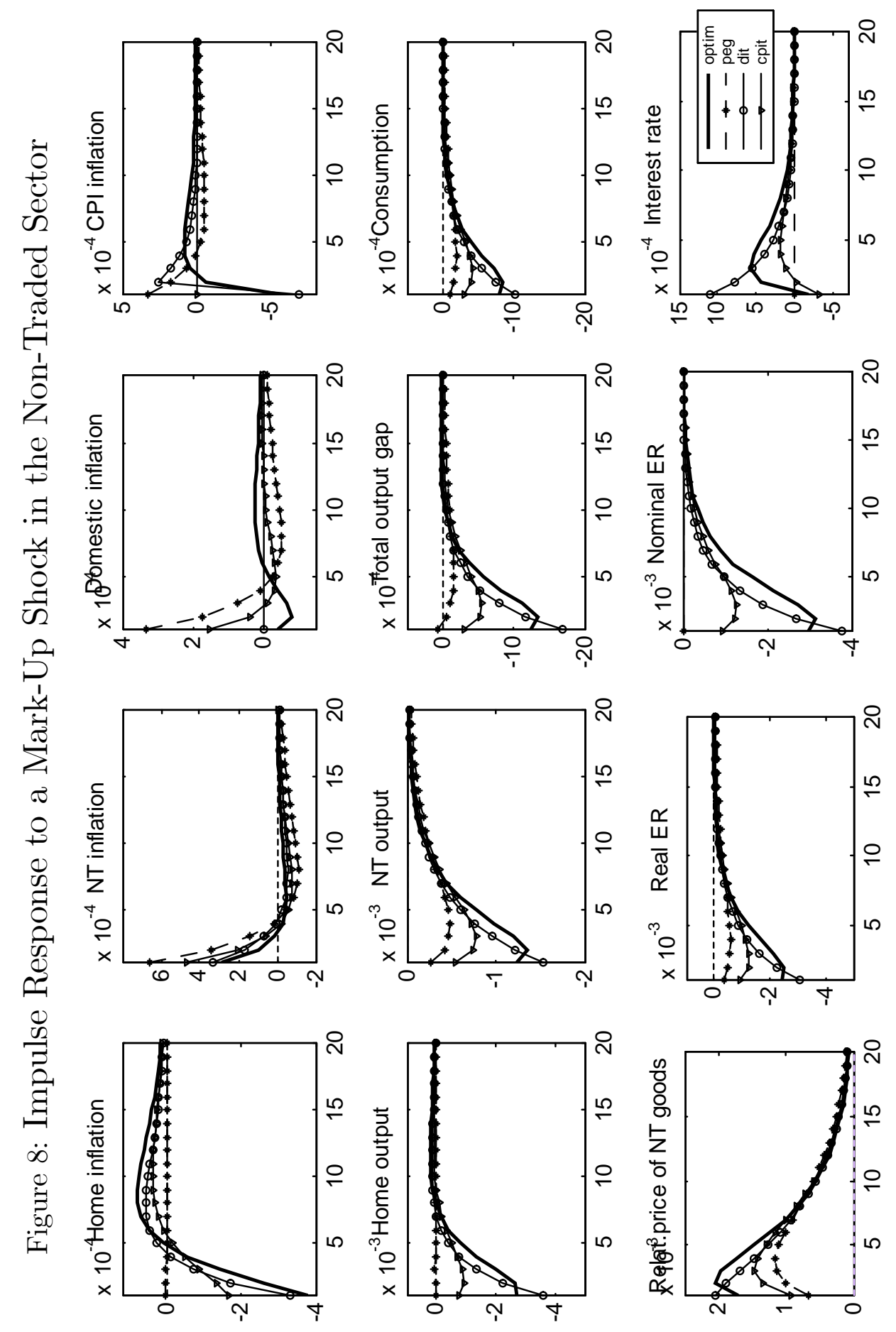




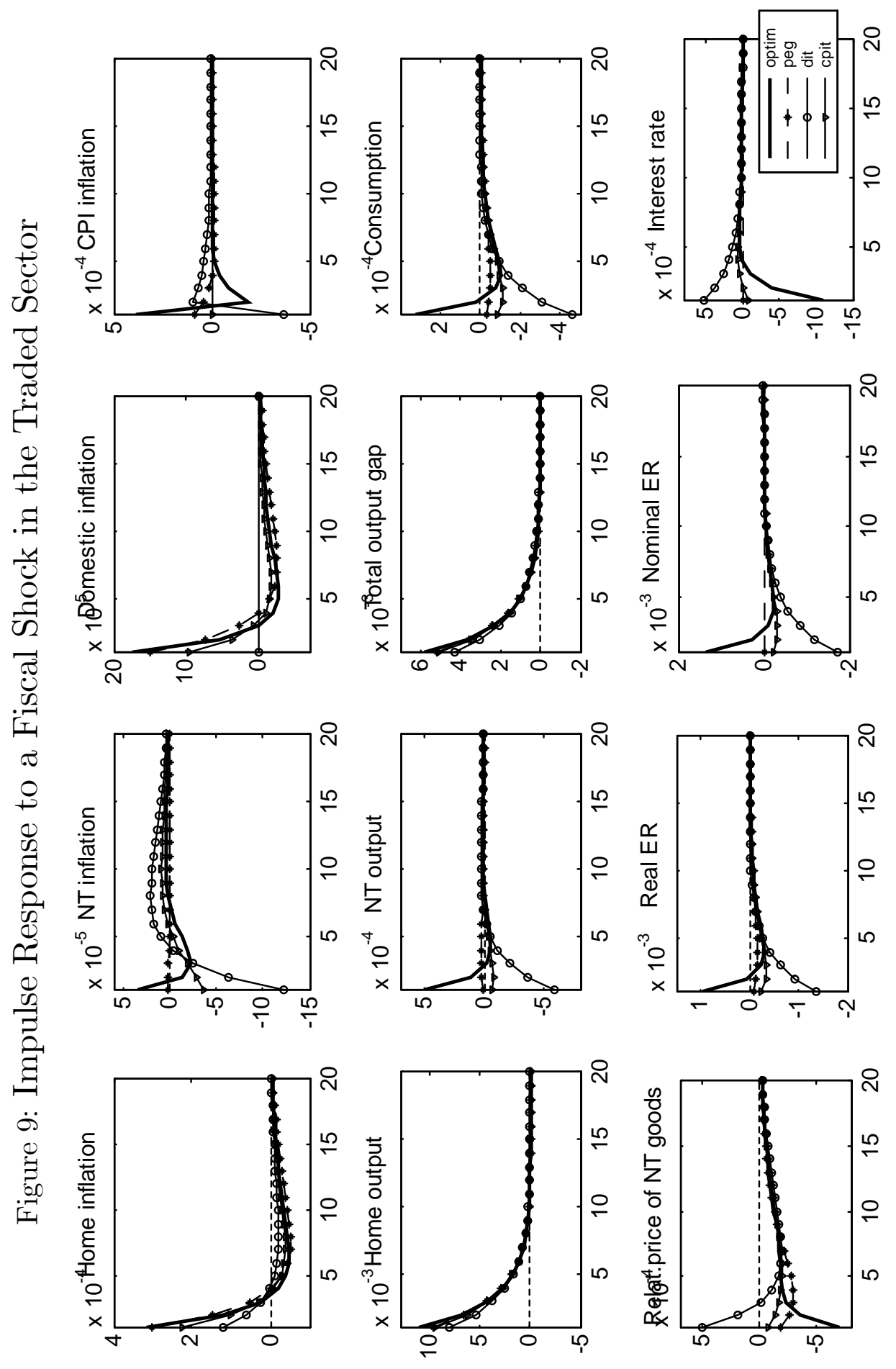




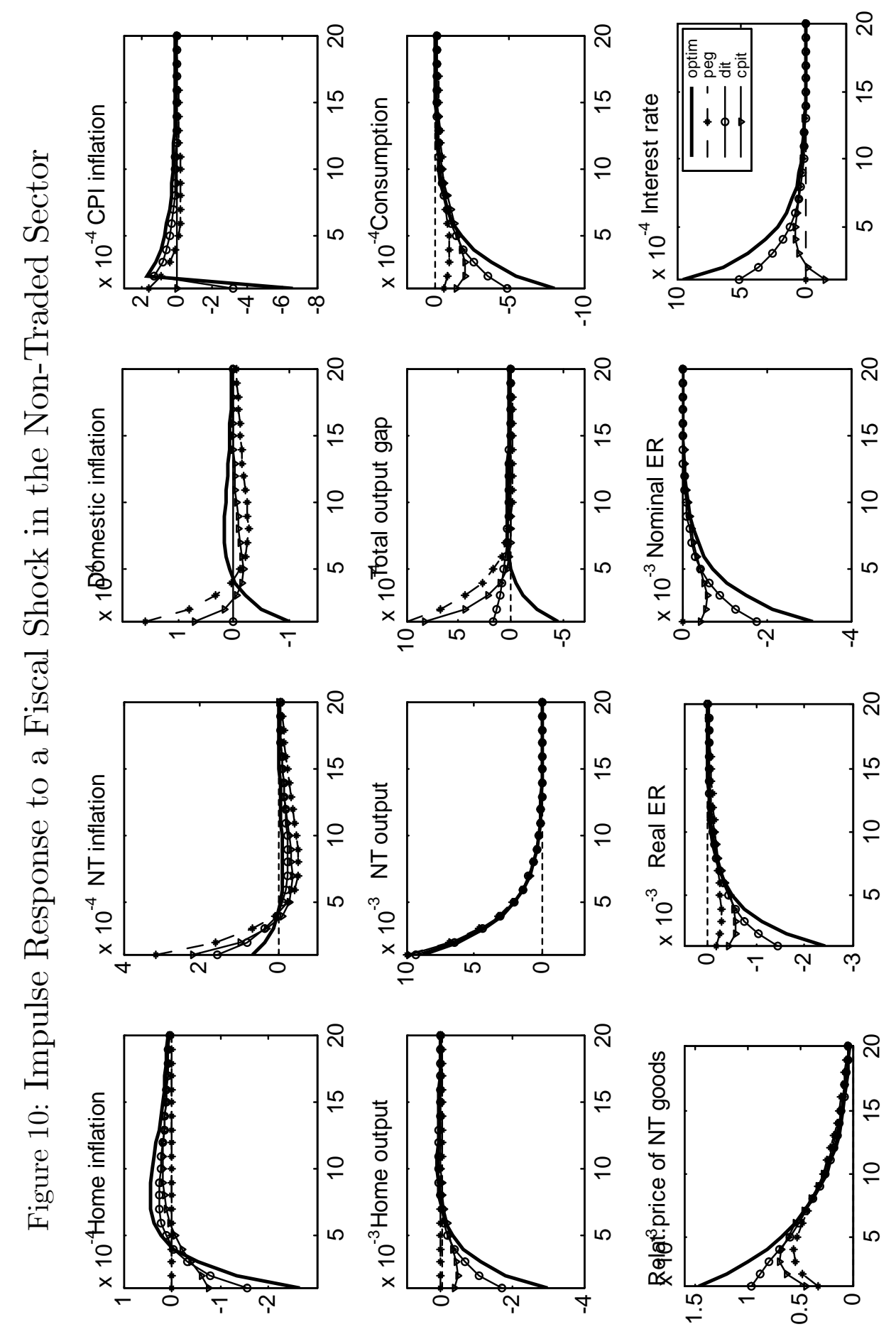


Individual researchers, as well as the on-line and printed versions of the CERGE-EI Working Papers (including their dissemination) were supported from the following institutional grants:

- Center of Advanced Political Economy Research [Centrum pro pokročilá politickoekonomická studia], No. LC542, (2005-2009),

- Economic Aspects of EU and EMU Entry [Ekonomické aspekty vstupu do Evropské unie a Evropské měnové unie], No. AVOZ70850503, (2005-2010);

- Economic Impact of European Integration on the Czech Republic [Ekonomické dopady evropské integrace na ČR], No. MSM0021620846, (2005-2011);

Specific research support and/or other grants the researchers/publications benefited from are acknowledged at the beginning of the Paper.

(c) Yuliya Rychalovska, 2008

All rights reserved. No part of this publication may be reproduced, stored in a retrieval system or transmitted in any form or by any means, electronic, mechanical or photocopying, recording, or otherwise without the prior permission of the publisher.

Published by

Charles University in Prague, Center for Economic Research and Graduate Education (CERGE) and

Economics Institute ASCR, v. v. i. (EI)

CERGE-El, Politických vězňů 7, 11121 Prague 1, tel.: +420 224005 153, Czech Republic.

Printed by CERGE-EI, Prague

Subscription: CERGE-EI homepage: http://www.cerge-ei.cz

Editors: Directors of CERGE and EI

Managing editors: Deputy Directors for Research of CERGE and EI

ISSN 1211-3298

ISBN 978-80-7343-181-5 (Univerzita Karlova. Centrum pro ekonomický výzkum

a doktorské studium)

ISBN 978-80-7344-170-8 (Národohospodářský ústav AV ČR, v. v. i.) 
CERGE-EI

P.O.BOX 882

Politických vězňů 7

11121 Praha 1

Czech Republic http://www.cerge-ei.cz 